\title{
método complexométrico para el análisis rápido del cemento portland
}

J. CALleja, J. M. FDEZ. PARIS y F. TRIVIÑo

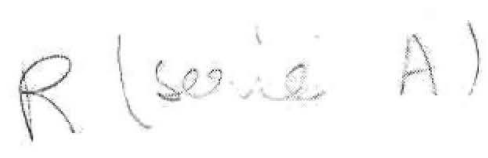

R E S U M E N

Se aborda en este trabajo el problema del análisis rápido del cemento y de los materiales silíeicos por medios puramente químicos y $\sin$ la ayuda que pudieran prestar otras técnicas físicas. Se adopta un método volumétrico easi general, basado en la eomplexometría, sin más excepeín que
la determinación gravimétriea acelerada de la silice. Para la determinación del óxido férrico se mantiene el procedimiento dicromatométrico por su sencillez y precisión.

Por complexometría se determinan con Complexona III 0,01 M la suma de alúmina $\mathrm{y}$ óxido férrico (la alúmina se calcula por diferencia), la suma de cal $y$ magnesia $y$, aparte, la cal (la magnesia se calcula por diferencia) y el trióxido de azufre.

El método se manifiesta tan precise y reproducible como los clásicos (dentro de las tolerancias de las Normas A.S. T. M.) y es mucho más rápido, puesto que permite efectuar el análisis completo del cemento en unas tres horas. Es también más sencillo, ya que ahorra pesadas $y$ caloinaciones (gravi. metrias) y no requiere el empleo de equipos especiales de colorimetria, fotometrí, espectrom

Es susceptible de sucesivas mejoras, $y$ en tal sentido se continúa trabajando en el Departamento de Química del I. E. T. c. c.

\section{INTRODUCGION.}

Tanto en la práctica de los laboratorios industriales como en la de los laboratorios de investigación, es por todos conceptos conveniente realizar las inevitables operaciones analíticas en el menor tiempo posible. En los laboratorios de fábrica, como consecuencia del riguroso control de las materias primas, y de los productos intermedios y terminados, el cual condiciona en todo momento la calidad de éstos y la buena marcha del proceso de fabricación. En los laboratorios de investigación, por cuanto que los resultados analíticos suelen influir en las decisiones acerca del rumbo de los trabajos, y la demora de aquéllos ocasiona también la de éstos.

En la industria del cemento son operaciones rutinarias las analíticas químicas relativas a las materias primas (calizas, margas, arcillas, yesos, carbones y sus cenizas), a los crudos de alimentación de los hornos, al clínker y a los cementos, así como a otros materiales auxiliares, siempre o casi siempre de carácter silícico, utilizados para la obtención de conglomerantes especiales. Tales son las bauxitas, las escorias de horno alto, las puzolanas naturales o artificiales, etc.

Pese a los avances ya realizados y a los que en la actualidad están en curso, los materiales silícicos, por su complejidad, no se prestan tan bien como otros (los metálicos, por ejem- 
plo) al empleo de métodos analíticos basados en técnicas físicas. De donde se infiere que del análisis químico como tal, difícilmente podrá prescindirse por el momento en el estudio de estos materiales.

El análisis químico completo de silicatos en general (clínker, cementos, morteros, hormigones) es una operación que, llevada a cabo aisladamente y por los métodos clásicos, viene a durar dos jornadas de trabajo. Incluye procedimientos gravimétricos y volumétricos, de los cuales los primeros son, naturalmente, lentos y se comprende la necesidad de disponer de métodos mucho más rápidos que, sin ceder ante los clásicos en precisión, sensibilidad y reproducibilidad (1) * y (2), permitan disponer de los resultados en el menor tiempo posible.

En el aspecto de la rapidez las técnicas físicas pueden ayudar mucho al análisis químico (3), pero sin llegar a desplazarlo totalmente. Por otra parte, los métodos de tipo físico, por sí solos, al menos en el caso de los materiales silicatados, y más concretamente en el del cemento, no pueden proporcionar datos completos, dada la complejidad del material que se estudia, por lo que, en general, resuelven sólo una parte del problema.

Todos o la mayoria de los procedimientos de naturaleza física: microscópicos, electrométricos, polarográficos, fotométricos, espectrográficos y difractométricos, exigen, en más o en menos, bien sea el concurso de personal idóneo, debidamente preparado y especializado que los aplique, o bien la preparación previa del problema analítico, antes de someterlo a la técnica utilizada. Frente a posibles o innegables ventajas (rapidez, adaptabilidad a un control de rutina), también tienen sus inconvenientes indiscutibles (imprecisión, limitaciones, etc.).

Por ello, estos métodos han tenido mayor aceptación y desarrollo como auxiliares de la investigación que como técnicas de control analítico industrial, si se exceptúan, en cierta medida, los procedimientos fotométricos (colorimetría) (4) y espectrográficos (fluorescencia de rayos $\mathrm{X})(5)$.

Por lo expuesto, cabe pensar que, de ser posible, el ideal por lo rápido, cómodo y sencillo, tanto para los laboratorios industriales y de ensayos, como incluso para los dedicados a la investigación, sería disponer de métodos químicos volumétricos ordinarios, aplicables a cada uno o, al menos, a la mayoría de los componentes del cemento o de los materiales silícicos analizados. En tal situación no se precisaria sino un equipo usual de laboratorio, más bien modesto (puesto que ni siquiera sería necesario emplear material de platino) y la labor analítica cuantitativa completa podría desarrollarla un operador corriente, no especializado, en un breve plazo de tiempo. Podria efectuarse en condiciones económicas sin competencia, dados los insignificantes gastos de instalación y mantenimiento, en comparación con los de las otras técnicas enumeradas.

En este sentido también la Química Analítica va dando sus soluciones, dentro del marco del análisis volumétrico. Una de estas soluciones es la aportada por los métodos llamados complexométricos, de desarrollo relativamente reciente, si bien sus principios son conocidos desde antiguo.

Es posible, incluso, la combinación de estos métodos volumétricos con alguna de las técnicas de tipo físico antes descritas, y particularmente con la fotometría y con la colorimetría, y también con los procedimientos electrométricos, para la determinación más exacta de los puntos finales en algunas valoraciones complexométricas.

Lo que sigue es un extracto con lo más destacado de cuanto se trata win extenso" en la monografía del mismo título que este trabajo, publicada recientemente (6), en la que pueden encontrarse los resultados experimentales y las conclusiones que han llevado a los autores al establecimiento del método que se describe.

$\left({ }^{\circ}\right)$ Todas las llamacias encerradas entre paréntesis, tales como la (1), (2), (3).., corresponden a la bibliografía inserta al final de la última parte de este trabajo. 


\section{METODOS ANALITICOS COMPLEXOMETRICOS APLICADOS A LOS MATERIALES SILICICOS.}

\subsection{Generalidades.}

Las complexonas, nombre genérico asignado al grupo de reactivos empleados en análisis complexométrico, son, en general, moléculas o iones orgánicos capaces de unirse a un ion metálico por valencias principales de naturaleza iónica y por valencias auxiliares de tipo coordinativo, para dar moléculas o iones complejos internos estables, poco disociados, fuertemente coloreados $\mathrm{y}$, a veces, solubles.

Los complejos internos son, pues, un caso particular de los aquelatos", y su formación corresponde al fenómeno general de la aquelacion», en virtud de la cual un ion metálico entra a formar parte de un anillo, ligándose al resto de las moléculas mediante valencias principales o secundarias.

La formación de complejos internos depende del catión y exige en la molécula orgánica la presencia de un grupo ácido, formador de sales $(-\mathrm{OH},-\mathrm{SH},-\mathrm{NH}$, etc.), y otro grupo, formador de un ion auxiliar $(\mathrm{O}=, \mathrm{S}=, \mathrm{N} \equiv$, etc.). Adernás, la situación de estos grupos en la molécula del reactivo ha de ser tal que permita la formación de anillos de 5 a 6 miembros, como más estables, sin un impedimento de tipo estérico (7), ni excesivas tensiones. A veces, de dos grupos iguales dentro de una misma molécula uno actúa como ácido y otro como auxiliar, tal como sucede con la dimetilglioxima y otras sustancias.

Más recientemente Schwarzenbach (8) ha designado como complexonas una serie de reactivos en los que los grupos ácidos son carboxílicos y los grupos auxiliares son amínicos secundarios $y$, sobre todo, terciarios. Los más sencillos de esta serie son el ácido aminodiacé tico (IDA) y el nitrilotriacético (NTA):

$$
\mathrm{HN}-\left(\mathrm{CH}_{2}-\mathrm{COOH}\right)_{2}
$$

IDA
$\mathrm{N}\left(\mathrm{CH}_{2}-\mathrm{COOH}\right)_{3}$

NTA

siguiéndoles los ácidos alquilenodiaminotetraacéticos en general (o sus sales derivadas):

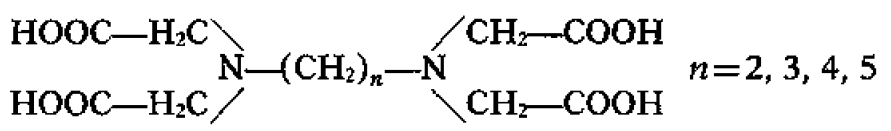

los propios derivados del ácido nitrilotriacético:<smiles>O=COCN(CC(=O)O)CC(=O)O</smiles>$$
n=1,2
$$

y el ácido uranildiacético (UDA):<smiles>O=C(O)CN(CC(=O)O)C1NONC(=O)O1</smiles>

entre los más estudiados.

(9) El grupo $-\mathrm{COOH}$ puede sustituirse por $-\mathrm{PO}_{3} \mathrm{H}$. para $n=1$, y por $-\mathrm{SO}_{1} \mathrm{H}$, para $n=2$. 
De entre ellos son fáciles de encontrar en el comercio el ácido nitrilotriacético (Complexona I). el ácido etilenodiaminotetraacético (Trilon B o Complexona II) y la sal disódica dihídratada del anterior (Complexona III). A los dos últimos (y particularmente al ácido) se les conoce asimismo con la designación EDTA, formada por las iniciales del nombre químico (Etileno Diamino Tetra Acético o Etileno Diamino Tetra Acetato), y con cierta frecuencia se les aplica la denominación de "versenatos» (9), entre otras menos corrientes ( «secuestrenos", "secuestroles", "titriplex", "trilones") (10) y (11).

Las complexonas no tienen, en realidad, un comportamiento especifico, y aunque, en general, las valencias y el $\mathrm{pH}$ elevados favorecen la «quelación», los $\mathrm{pH}$ óptimos dependen de los cationes, pues suelen ser más estables los complejos formados con los divalentes.

En análisis volumétrico se emplean las Complexonas I, II, III y preferentemente esta última, el Etileno Diamino Tetra Acetato disódico:<smiles>N#CCN(CCN(CC(=O)O)CC(=O)O)CC(=O)O</smiles>

con dos moléculas de agua de cristalización, fórmula que a veces se representa en forma abreviada por $\mathrm{AH}_{2} \mathrm{Na}_{2} \cdot 2 \mathrm{H}_{2} \mathrm{O}$ o, más frecuentemente, por $\mathrm{YH}_{2} \mathrm{Na}_{2} \cdot 2 \mathrm{H}_{2} \mathrm{O}$.

En presencia de indicadores específicos idóneos y operando en medios de $\mathrm{pH}$ adecuado para la formación estequiométrica del complejo que se desee obtener, ségún sus condiciones de estabilidad, se efectúan valoraciones de cationes diferentes, pudiéndose trabajar directamente o por retorno, como en las volumetrías ordinarias, incluso por alcalimetría en algún caso, dado que la formación de complejo por parte de un catión, cualquiera que sea su polivalencia, libera estequiométricamente los dos hidrogeniones de los dos grupos carboxílicos, puesto que el compuesto que se forma contiene siempre un solo catión en forma de complejo (12).

- El mecanismo de la formación de un complejo cristalizable entre la complexona III y los iones de un metal divalente $M e^{2+}$ queda esquematizado así:

$$
\mathrm{YNa}_{2} \mathrm{H}_{2} \cdot 2 \mathrm{H}_{2} \mathrm{O}+\mathrm{Me}^{2+}+n \mathrm{H}_{2} \mathrm{O}=\mathrm{YNa}_{2} \mathrm{Me} \cdot n \mathrm{H}_{2} \mathrm{O}+2 \mathrm{H}_{3} \mathrm{O}^{+}
$$

lo que explica que pueda operarse cuantitativamente con el complejo metálico formado o con los dos iones hidronio liberados, utilizando en este último caso un indicador de acidez-basicidad adecuado.

La formación del complejo queda patente en disolución cuando va acompañada de un cambio de color, según el siguiente esquema general:

$$
\underset{\text { incoloro }}{\mathrm{YNa}_{2} \mathrm{H}_{2} \cdot 2 \mathrm{H}_{2} \mathrm{O}}+\underset{\substack{\text { incol. } \\ \text { o } \\ \text { color } \mathrm{a}}}{\mathrm{Me}^{2+}}=\underset{\text { color b }}{\mathrm{YNa}_{2} \mathrm{Me}}+2 \mathrm{H}_{3} \mathrm{O}^{+}
$$

Con la Complexona II, abreviadamente representada por $\mathrm{YH}_{4}$, los esquemas correspondientes serían éstos:

$$
\begin{aligned}
\mathrm{YH}_{4} & =\mathrm{Y}^{4-} \\
\mathrm{Y}^{4-}+\mathrm{Me}^{\mathrm{n}+} & =\underset{\text { incol. }}{(\mathrm{YMe})^{(4-n)-}}+{ }^{\text {coloreado }}
\end{aligned}
$$

o bien:

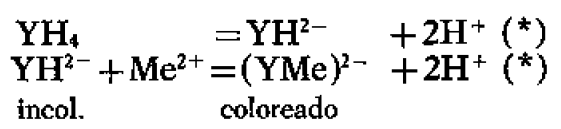

(*) Además de la forma aniónica $\mathrm{Y}^{4-}$, totalmente disociada, y la $\mathrm{YH}_{2}{ }^{2-}$, intermedia $y$ más frecuente a $\mathrm{pH}$ próximos a la neutralidad, existen las formas $\mathrm{YH}^{\mathrm{j}-}, \mathrm{YH}_{\mathbf{4}}$, en proporciones dependientes del $\mathrm{pH}$. 
ya que en disolución neutra el ácido etilenodiaminotetraacético existe en la forma disociada $\mathrm{YH}_{2}^{2+}+2 \mathrm{H}^{+}$, probablemente por la doble estructura betaínica que Schwarzenbach (8) le atribuye:

$$
\left[\begin{array}{cc}
\ldots \ldots \ldots . \mathrm{H}^{+} & \mathrm{H}^{+} \ldots \ldots \ldots . . \\
\hdashline \mathrm{OOC}-\mathrm{H}_{2} \mathrm{C} & \mathrm{CH}_{2}-\mathrm{COO}^{-} \\
\mathrm{N}-\mathrm{CH}_{2}-\mathrm{CH}_{2}-\mathrm{N} & -\mathrm{CH}_{2}-\mathrm{COO}^{-}
\end{array}\right]
$$

La determinación del punto final en las volumetrías complexométricas puede hacerse de una forma visual, según lo que antecede, por medio de indicadores de acidez-basicidad, cuyo cambio de color depende del pH:

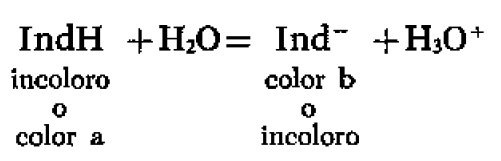

También puede hacerse mediante indicadores de metales o cationes, cuando el complejo indicador-metal tiene un color distinto que el del indicador libre y el cambio de color depende del pH. El mecanismo es, en esquema, el siguiente:

$$
\begin{aligned}
& \text { 2Ind- } \quad+\mathrm{Me}^{2+}=(\text { Ind })_{2} \mathrm{Me} \\
& \text { incoloro color } b \\
& \text { color a incoloro } \\
& \mathrm{YNa}_{2} \mathrm{H}_{2} \cdot 2 \mathrm{H}_{2} \mathrm{O}+\mathrm{Me}^{2+}=\mathrm{YNa}_{2} \mathrm{Me}+2 \mathrm{H}_{3} \mathrm{O}^{+} \\
& \text {incoloro incoloro }
\end{aligned}
$$

Si el complejo (Ind) ${ }_{2} \mathrm{Me}$ es más débil o inestable que el complejo $\mathrm{YNa}_{2} \mathrm{Me}$, el equilibrio (I) se desplazará hacia la izquierda y el (II) hacia la derecha, de modo que el primer complejo desaparece a expensas de la formación del segundo. Cuando todo el complejo (Ind) ${ }_{2} \mathrm{Me}$ ha desaparecido, es decir, cuando se ha formado todo el complejo $\mathrm{YNa}_{2} \mathrm{Me}$ que puede formarse, se apreciará un cambio brusco del color $b$ al incoloro, o del incoloro al color $a$, según el equilibrio (I). En la realidad, el mecanismo es más complicado, por una parte, porque, en general, el equilibrio (I) no es insensible al $\mathrm{pH}$, bien a causa del indicador en sí, o del complejo (Ind) $)_{2} \mathrm{Me}$ y, por otra, porque el desplazamiento del equilibrio (II) hacia la derecha lleva implícita una disminución del pH. De aquí que en las valoraciones complexométricas deba mantenerse fijo el pH adecuado, operando en sistemas amortiguados, ya que los indicadores metálicos no sólo son indicadores del $\mathrm{pM}$, sino también del $\mathrm{pH}$.

Debido a esto, pocas de las posibles sustancias capaces de dar reacciones coloreadas con iones metálicos son aprovechables como indicadores en complexometría, pues, según Flaschka (11), deben reunir toda una serie de condiciones, a saber:

a) Tener sensibilidad en las proximidades del punto final.

b) Tener especificidad o selectividad exenta de interferencias.

c) Presentar una diferencia de color apreciable entre el indicador libre y el complejo indicador-metal.

d) Tener este último estabilidad suficiente para que se cumpla la condición $a$ ).

e) Tener el complejo EDTA-metal mayor estabilidad que el complejo indicador-metal.

f) Transcurrir con rapidez la reacción entre el EDTA y el complejo indicador-metal (compuestos solubles, en general) para la exacta localización del punto final. Eventualmente éste puede detectarse también por medio de indicadores "redox*. 
Entre los indicadores metálicos más empleados en complexometría están el Negro de eriocromo $\mathrm{T}$, derivado nitrosulfónico del 0,0-dioxi-azo-naftaleno, la Murexida (purpurato amónico), la Metalftaleína, el PAN [1-(2-piril-azo)-2-naftol], el Tiron (sal disódica del ácido 3,5-pirocatequindisulfónico), el Violeta de pirocatequina, el eriocromoazurol $\mathrm{S}$, la eriocromocianina $\mathrm{R}$ y el Cincon, con grupos sulfónicos y fenólicos o carboxílicos, o ambos conjuntamente, en cada caso, así como la Ditizona (difeniltiocarbazona), etc.

Por la circunstancia que, según Flaschka, debe reunir cualquier indicador de complexometría, aparte de la estabilidad de los complejos metálicos de las complexonas, hay que tener presente la condición, lenta en general, de la formación de estos compuestos, aspecto muy de tener en cuenta en las aplicaciones cuantitativas de estos métodos (11).

Los tipos de valoración a que las complexometrías pueden dar lugar, aparte de los alcalimétricos ya citados, y que pueden ser directos o por retroceso, son los siguientes:

1. Volumetría directa, en que el problema, en disolución amortiguada de $\mathrm{pH}$ adecuado, se valora con una disolución patrón de complexona. Se puede aplicar este tipo de valoración: a) cuando el ion metálico que se determina permanece en disolución en las condiciones de trabajo; $b$ ) cuando existe un indicador adecuado, de punto de viraje neto, en función del $\mathrm{pH}$; c) cuando el complejo es suficientemente estable, y $d$ ) cuando éste se forma con la suficiente rapidez.

2. Volumetria de retorno o retroceso, en que se añade al problema un exceso conocido de una disolución patrón de complexona, se ajusta el $\mathrm{pH}$ mediante un sistema amortiguador apropiado, se añade el indicador y se valora el excedente de complexona con una disolución patrón de una sal metálica adecuada. Se suele aplicar cuando no se dan las condiciones $a$ ), $b$ ) y $c$ ) antes expuestas, e incluso cuando la volumetría directa es posible.

3. Volumetría de sustitución o desplazamiento, en que, por no darse las circunstancias anteriores, un ion metálico no es determinable por el método directo o por el de retorno, siéndole en cambio otro ión al que aquél desplaza. Se aplica a veces con éxito cuando no se da la condición $d$ ) de las antes indicadas.

4. Volumetrías indirectas, en las que se precipita estequiométrica y cuantitativamente un anión o catión y se valora por complexometria, bien sea otro catión del precipitado separado, o bien el exceso de reactivo precipitante, en el filtrado. Se pueden aplicar a la determinación de alcalinos que no forman complejos, asi como a la de aniones tales como fosfatos y, tal vez, silicatos.

En general, las constantes de estabilidad (inversas de las constantes de equilibrio de disociación) de los complejos formados por una complexona y distintos metales, no son tan diferentes que dejen márgenes de selectividad tales que permitan la determinación individual de cada uno de aquéllos cuando sus iones se encuentran juntos. A veces se puede conseguir, no obstante, por aenmascaramiento" o "apantallamiento", es decir, evitando la formación de complejos por parte de alguno o algunos de dichos iones. Ello se logra, o por modificación del $\mathrm{pH}$ para que determinados complejos no se formen, o, si se han formado, se disocien totalmente, o por formación de otros complejos más estables que los de la complexona (cianuros, con trietanolamina, etc., según los casos), o por precipitación (sin filtración separadora), o por oxidación o reducción del catión que forma complejo, a un grado de valencia en que no le forme, o el formado sea mucho más débil.

El "enmascaramiento" se aplica también para impedir el bloqueo de los indicadores por determinados cationes, incluso en cantidades mínimas (trazas). Las propias complexonas pueden actuar como agentes «enmascarantes», lo cual es preciso tener en cuenta en las complexometrías de retorno. La acción del eenmascaramiento" por parte de un reactivo puede evitarse o anularse por la actuación de otros llamados «desenmascarantes».

Las volumetrías complexométricas requieren el empleo de agua bidestilada o, mejor aún, desionizada, para preparar las disoluciones problema y reactivas; el control rigurosísimo del 
$\mathrm{pH}$, por amortiguamiento de la disolución con un sistema adecuado y por neutralización previa, si es preciso (siempre con hidróxido sódico y nunca con hidróxido amónico, mientras no se indique otra cosa); el empleo de indicadores de preparación reciente y, preferentemente, en forma sólida y en el mismo momento de proceder a la valoración, y, finalmente, la conservación de los reactivos en frascos de vidrio de borosilicatos o, mejor, de plástico (polietileno). Todo esto tiende a evitar interferencias, imprecisiones o errores en la apreciación de los virajes de los indicadores $y$, en definitiva, errores en los resultados de los métodos.

Las complexonas pueden considerarse como sustancias patrones primarios para la preparación de disoluciones reactivas. La Complexona III, previa desecación a $150^{\circ} \mathrm{C}$, hasta peso constante (sal anhidra), o a $80^{\circ} \mathrm{C}$ durante 2 a 3 días (sal dihidratada), lo cual es preferible.

La Complexona II, previa desecación a $15^{\circ} \mathrm{C}$ hasta peso constante. Las disoluciones conservan su título indefinidamente y pueden contrastarse, si se desea o es preciso, frente a disoluciones patrón de sạles de zinc.

Además de la primitiva publicación de Schwarzenbach sobre aplicación de las complexonas al análisis cuantitativo químico (8), y de otras posteriores y de carácter general sobre el mismo tema (11), (13) y (14), han ido apareciendo otras en que se destaca la adaptación de la complexometría a los métodos potenciométricos (15) y amperiométricos (16), así como a los procesos «redox» (17) y a volumetrías sin indicadores metálicos (18).

En cuanto a indicadores, muchos son los ya puestos en uso (19) (20), y continuamente están apareciendo otros nuevos, de empleo más o menos general o específico (21).

Con respecto a los reactivos, es decir, a las sustancias capaces de formar complejos con unos u otros cationes, y en unas u otras condiciones, sucede lo mismo: cada día se extiende y generaliza el empleo de más y más (22), (23) y (24), buscándose la mayor resistencia o estabilidad de los complejos formados y la mejor actuación de los reactivos en medios oxidantes (23) o en otras condiciones analíticas.

\subsection{Métodos generales de análisis complexométrico de cementos.}

Entre los procedimientos generales de anál sis cuantitativo completo de materiales silícicos (incluidos los cementos) pueden establecerse tres grandes grupos que marcan tres tendencias modernas en este problema: el de los procedimientos fotométricos y el de los röntgenográ. ficos, de naturaleza física ambos, y el de los complexométricos, de naturaleza genuinamente química (25) y (26).

En cuanto a los procedimientos complexométricos cabe decir que son varios los métodos y marchas analíticas que se han descrito y propuesto para el análisis, más o menos completo, de los cementos y materiales silícicos similares. Recientemente se ha publicado un estudio bibliográfico crítico y comparativo de buena parte de ellos (27).

En general, casi todos adolecen de alguna insuficiencia, muchas veces superable, por lo cual son susceptibles de perfeccionamientos.

Así, por ejemplo, la mayoría de estos métodos, en el caso de los cementos, ignora, pese a su importancia, la determinación de $\mathrm{SO}_{3}(12),(28),(29),(30),(31)$ y (32), o recomienda se efectúe por el procedimiento gravimétrico clásico (33). Algún otro ignora asimismo la determinación de la magnesia (30).

Por otra parte, en casi todos ellos se determina $\mathrm{TiO}_{2}$, junto con la alúmina (o con el óxido férrico) (29), lo que obliga a hacer una determinación $\mathrm{TiO}_{2}$ en muestra aparte, si se quiere tener la alúmina y el óxido férrico como tales, datos interesantes siempre, e imprescindibles en el cálculo de la composición potencial del cemento. 
Algunos de los procedimientos en uso, dentro de empresas fabriles privadas, recurren al empleo de cianuro potásico para favorecer la formación de complejos de ciertos elementos (calcio y magnesio) en determinadas condiciones (28) y (29), lo que no deja de ser una circunstancia desfavorable por el peligro que supone dicho empleo, si se tienen en cuenta las características especiales que concurren en la mayoría de los operarios analistas de los laboratorios de control de las fábricas.

Otros métodos no se apartan del todo de la gravimetria en lo que respecta a la determinación de los sesquióxidos (29), (32), (33) y (34). En general, todos aceptan la determinación gravimétrica de la sílice, si bien alguno de ellos se aventura a darla por diferencia (28), sin separarla, lo cual, en el caso del cemento y de las materias primas para el mismo, es inadmisible.

Hay procedimientos que recurren al empleo de colorimetros, lo que indudablemente complica las técnicas y los equipos necesarios (25), (28) y (35).

Aparte de las características diferenciales señaladas, los métodos descritos en la bibliografía se distinguen por el empleo de unos u otros indicadores en las valoraciones complexométricas de los elementos implicados, y en las condiciones de trabajo que aquéllos imponen, particularmente por lo que se refiere al $\mathrm{pH}$.

Así, por ejemplo, en la determinación de la alúmina puede utilizarse la Ditizona a pH 6 (35) o a pH 4,5 (12), el ferrocianuro potásico a pH 5 (28), ó 6 (30), ó 5-6 (36), operando en todos los casos por retorno y valorando el exceso de EDTA con disolución de $\mathrm{Zn}^{2+}$; también puede emplearse el PAN-complexonato de cobre a pH 3 (29), (36) y (37), valorando el exceso de EDTA con $\mathrm{Al}^{3+}\left(29 \mathrm{y}(36)\right.$, o con $\mathrm{Cu}^{2+}(37)$, o al dicromato potásico a $\mathrm{pH} 4,5$, valorando $\mathrm{el} \mathrm{ex}$ ceso de EDTA con $\mathrm{Pb}^{2+}(29)$.

En la determinación del óxido férrico, cuando no se mantienen los métodos clásicos (por ejemplo, la dicromatometría (12) y (33), o el empleo de $\mathrm{Ti}^{3+}$ como reactivo de valoración) puede trabajarse con indicador de Ditizona a $\mathrm{pH}$ 6(35) con ácido sulfosalicílico a $\mathrm{pH} 3(29)$ y (38), con Tíron-5 a pH 3 (31), o con ácido salicílico a $\mathrm{pH}$ 6(30); en el primer caso la valoración del exceso de EDTA por retorno se hace con disolución de $\mathrm{Zn}^{2+}$, en el segundo y tercero no existe valoración de retorno, por ser directas las determinaciones, $y$ en el cuarto se puede llevar a cabo con $\mathrm{Fe}^{3+}$.

La determinación de la cal puede hacerse con indicador de Murexida a $\mathrm{pH}$ 10-13 (12) y (39), o a pH 12-13 (30), (32), (37) y (40), previa separación de la sílice y los sesquióxidos (12), (29), (31), (32) y (39), o sin separación (29), (30), (32), (36) y (37), empleando en tal caso trietanolamina para evitar la interferencia del aluminio, del titanio y del hierro; también puede utilizarse la mezcla de Murexida y verde de naftol B a pH 12 (33) y (36). Otros métodos recurren a la determinación fotométrica del calcio en la misma fracción del problema en que, por vía también fotométrica, se determinan los álcalis (28).

En la determinación de la magnesia, o más bien en la de la suma de cal y magnesia (puesto que aquélla se suele hallar por diferencia entre el valor correspondiente de la suma $\mathrm{CaO}+$ $+\mathrm{MgO}$ y el correspondiente a $\mathrm{CaO}$ ) se suele utilizar como indicador Negro de eriocromo $\mathrm{T}$ a pH 10-11 y previa separación del aluminio, del titanio y del hierro (12), (28), (29), (31), (32), (33) y (39), en presencia (29) o no (12), (28) y (31) de trietanolamina, o sin separación de los citados elementos (29) y (37), lo que obliga a reducir el hierro férrico a ferroso con ácido ascórbico y a emplear cianuro potásico, o a sustituir el indicador Negro de eriocromo $\mathrm{T}$ por la ortocresolftaleina (37); también se procede así, a veces, aún con separación de los elementos mencionados (28). Se ha pretendido, incluso, la determinación aislada de la magnesia, independiente de la cal, por separación de ésta (41), pero sin que el método haya tenido interés práctico ni aceptación en el caso del cemento y de los materiales silícicos.

En Italia (29) y (31), en Alemania (42) y en la Unión Soviética (43), entro otros países, se ha trabajado en el tema del análisis complexométrico, más o menos completo, de los cementos. Aparte de las referencias ya hechas a trabajos espanioles (44), (45), (46) y (47), ha habido otras tentativas en el mismo sentido (48), así como también portuguesas (12). En general, todos los métodos propuestos y descritos parten del trabajo original de Schwarzenbach (8). 
Es de advertir que, por lo que respecta a muchas de sus características, y a la mayor rapidez y sencillez, en vista del ahorro y simplificación de operaciones, todos estos métodos admitirían perfeccionamientos.

\subsection{Método del I. E. T. c. c.}

Por cuanto queda expuesto, y en vista de los trabajos realizados por el Departamento de Química del I. E. T. c. c. en el campo de la complexometría aplicada al análisis del cemento y otros materiales similares, este Departamento ha elaborado un método que se juzga más ventajoso que los consultados y estudiados, y que se ve avalado por los resultados experimentales fruto de una labor de equipo desarrollada a lo largo de dos años. Los detalles de la marcha analítica completa son los indicados a continuación, los cuales pueden verse desarrollados en forma gráfica en los esquemas 1 y 2.

\subsubsection{Observaciones de carácter general.}

A semejanza de las recomendaciones hechas por Ford (49) en un bosquejo de lo que pudiera ser una Instrucción o Manual para analistas de cemento, se hace en lo que sigue una serie de observaciones generales (y aún particulares) relativas a todos los principales aspec-

\section{ESQUEMA GENERAL DEL ANALISIS COMPLEXOMETRICO DEL CEMENTO PORTLAND}

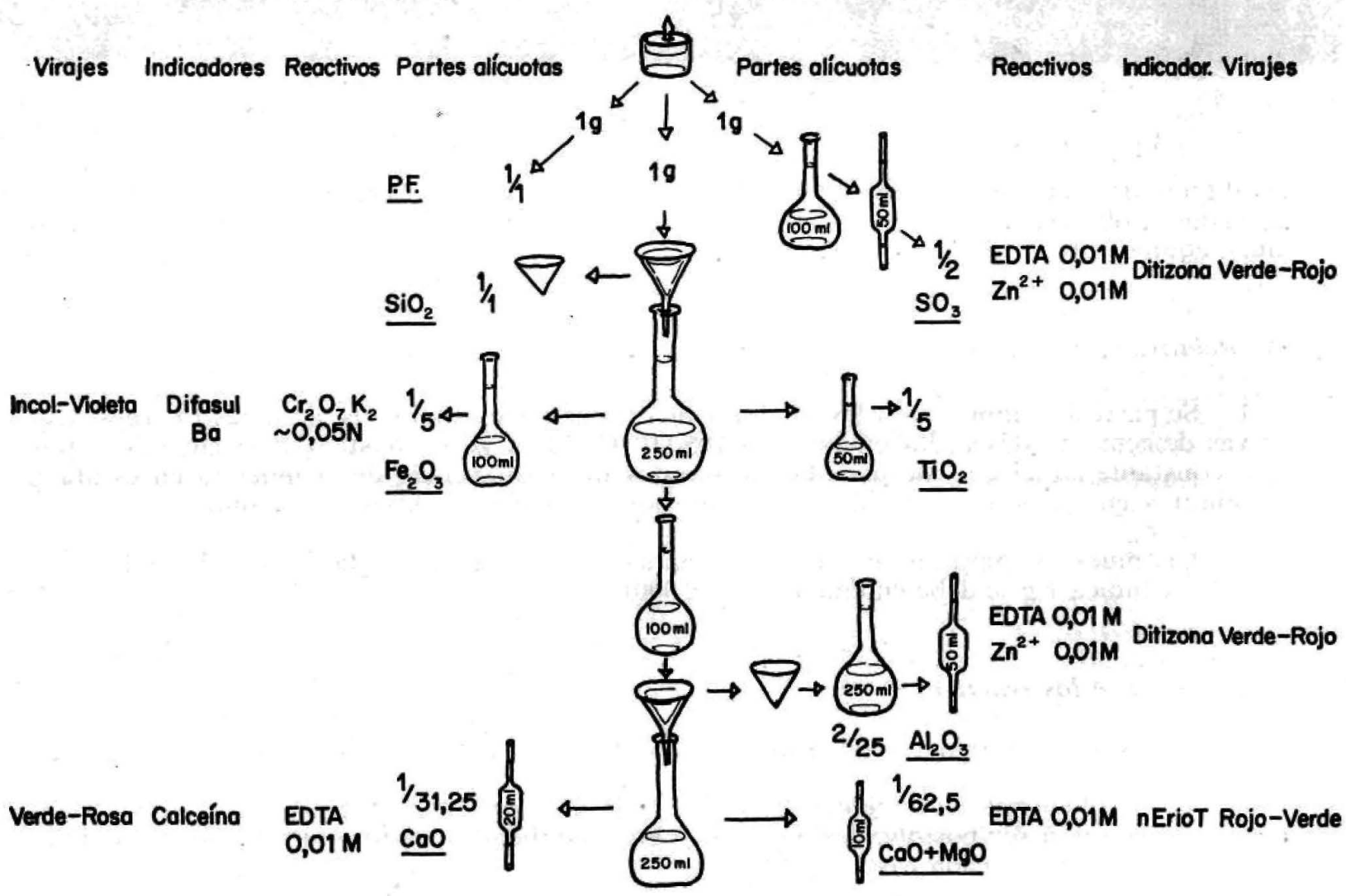




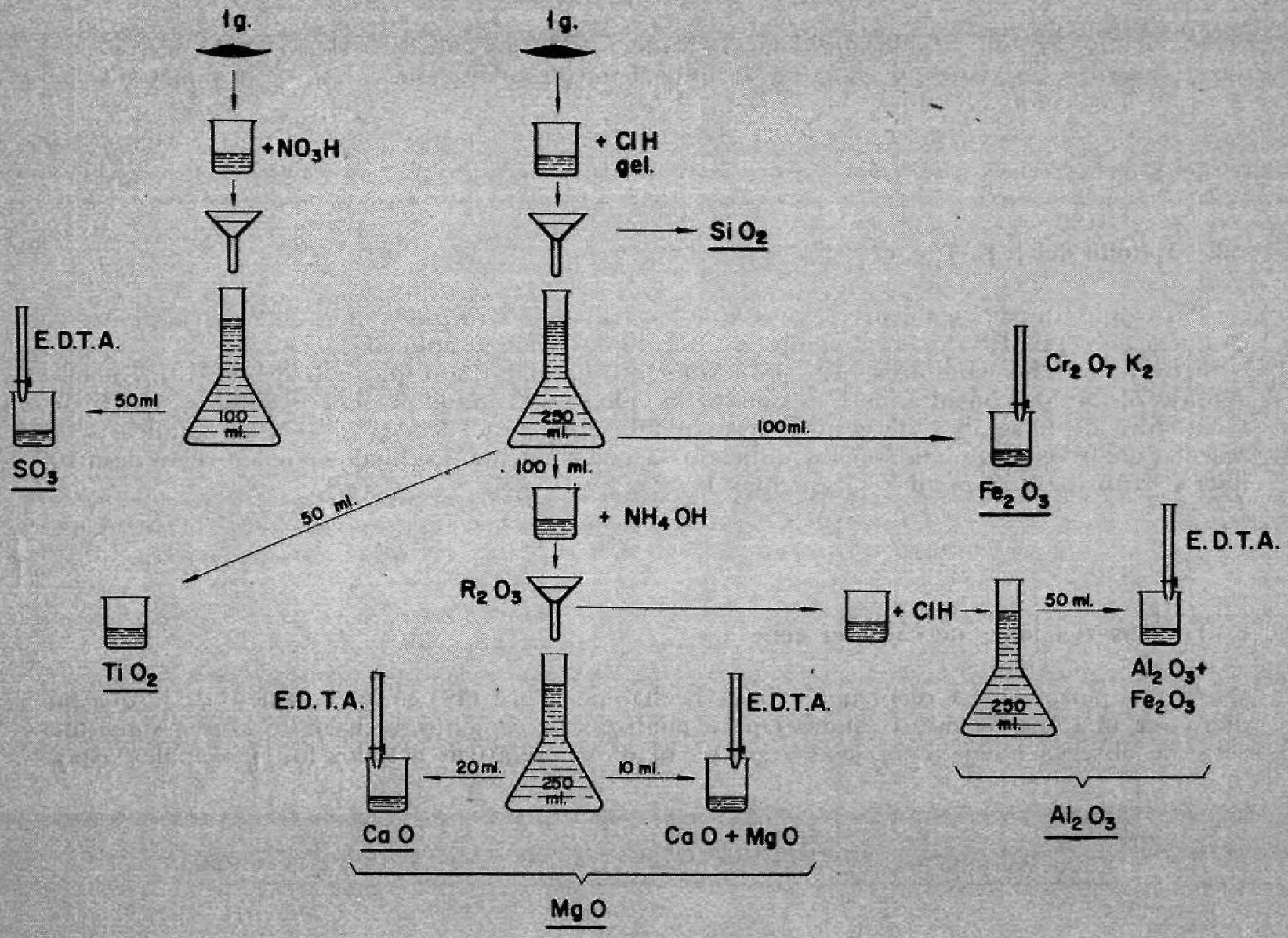

tos dignos de atención, con consideración especial de los específicos de la complexometria. La primera observación general se refiere a la limpieza y orden de lugares de trabajo, aparatos, equipos, material y reactivos.

\section{a) Relativas a las muestras.}

1. Se partirá siempre, para las distintas determinaciones analíticas, de muestras representativas de cemento desecadas en estufa a $105-110^{\circ} \mathrm{C}$, hasta peso constante. Se entenderá por peso constante aquel que, después de 45 minutos de permanencia de la muestra en estufa y 15 minutos en un desecador, difiera del anterior en menos de 0,0002 de gramo.

2. Las muestras para las distintas determinaciones se pesarán a la décima de miligramo. Cuando se indica $1 \mathrm{~g}$ se debe entender $1 \mathrm{~g} \pm 0,0001$.

\section{b) Relativas a los reactivos.}

1. Se utilizarán productos purísimos, en calidad de reactivos analíticos.

2. Las disoluciones y diluciones, y lavados que lo requieran, se efectuarán siempre con agua destilada y, a ser posible, desionizada, sobreentendiéndose esto aun cuando no se indique explícitamente en cada caso. 
3. Por ácidos concentrados se entenderá los de peso específico o riqueza siguientes:

\begin{tabular}{|c|c|}
\hline 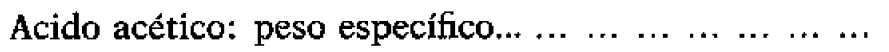 & 1,05 ó $99,5 \%$ \\
\hline Acido clorhídrico: peso específico. & 1,19 ó $37,5 \%$ \\
\hline Acido fluorhídrico: peso específico & 1,15 ó 48 \\
\hline Acido nítrico: peso específico... ... & 1,42 ó 70 \\
\hline Acido perclórico: peso específico... & $1,67 \mathrm{c}$ \\
\hline Acido fosfórico: peso específico $\ldots \ldots \ldots \ldots \ldots$ & 1,70 \\
\hline Acido sulfúrico: peso específico $\ldots \ldots \ldots \ldots \ldots$ & 1,84 \\
\hline
\end{tabular}

Estos pesos específicos están referidos a $20^{\circ} \mathrm{C} / 4^{\circ} \mathrm{C}$.

4. Por amoníaco concentrado se entenderá el producto purisimo de peso específico 0,90 .

5. La Complexona III, sal disódica dihidratada del ácido etilenodiaminotetraacético, de peso molecular 372,25 se considerará como sustancia patrón primario, previa desecación a $80^{\circ} \mathrm{C}$ durante 12 horas. Se utilizará en disolución $0,01 \mathrm{M}(3,7225 \mathrm{~g} /$ litro $)$.

6. El dicromato potásico $\mathrm{Cr}_{2} \mathrm{O}_{7} \mathrm{~K}_{2}$ se considera como sustancia patrón primario, previa cristalización. Se utilizará en disolución de $2,4570 \mathrm{~g} / 1$, tal que su equivalencia en $\mathrm{Fe}_{2} \mathrm{O}_{3}$ sea de $0,004 \mathrm{~g} / \mathrm{mI}$.

7. La disolución $0,01 \mathrm{M}$ de $\mathrm{Zn}^{2+}$ para valorar por retorno al exceso de Complexona III en las determinaciones de alúmina y trióxido de azufre se obtiene disolviendo en agua y ácido clorhídrico $(0,8138 \mathrm{~g} / \mathrm{l})$ óxido de zinc previamente calcinado a $1.000^{\circ} \mathrm{C}$ durante una hora. Esta disolución deberá contrastarse con la de Complexona III para determinar su equivalencia o factor.

8. Deberá cuidarse de la pureza de los indicadores y de la duración y estado de utilización de sus disoluciones.

\section{c) Relativas al material.}

1. La balanza analítica deberá apreciar holgadamente la décima de miligramo. Deben contrastarse las pesas con frecuencia.

2. El material aforado será en todo caso rigurosamente contrastado, a ser posible por cada operador que lo utilice.

3. Se recomienda muy especialmente, siempre que sea posible, el empleo de material de polietileno para guardar reactivos y disoluciones patrón.

4. Los desecadores deben recargarse con el agente desecante al menor indicio de agotamiento o deterioro.

5. Los crisoles de platino deben limpiarse con pirosulfato potásico $\mathrm{S}_{2} \mathrm{O}_{7} \mathrm{~K}_{2}$ y ácido clorhídrico diluido (1:1) y hay que evitar su contacto con partículas de hierro y otros materiales nocivos.

6. Los crisoles de porcelana deben limpiarse rascándolos interiormente con una espátula y empleando un chorro fuerte de aire, en vez de lavarlos.

\section{d) Relativas a las operaciones.}

1. Las pesadas, mientras no se indique otra cosa, deben hacerse con aproximación de 0,1 miligramo. 
2. Las ebulliciones deben efectuarse en vasijas adecuadas en cada caso. Cuando se utilicen vasos, éstos deben cubrirse con vidrios de reloj para evitar salpicaduras al exterior. Debe mantenerse introducida en ellos una varilla de vidrio para evitar sobrecalefacciones.

3. La digestión de los precipitados, así como el reposo y sedimentación de los mismos, habrá de llevarse a cabo en las condiciones apropiadas para cada caso: sobre baños de vapor de agua, sobre placa calefactora, a la temperatura ambiente, o enfriando en corriente de agua o en hielo.

4. La filtración debe efectuarse en embudos de $606,5 \mathrm{~cm}$ de diámetro con pico largo y ángulo de 45 grados. Deberá emplearse papel adecuado en cada caso. El vertido del líquido en el embudo se hará con ayuda de una varilla de vidrio, y se procurará que no sobrepase de $5 \mathrm{~mm}$ a partir del borde del papel. Los vasos de precipitados se enjuagarán con agua destilada o disolución de lavado y se retirará de ellos toda partícula de precipitado, con ayuda de un trozo de caucho engastado en el extremo de una varilla de vidrio.

5. Las evaporaciones se harán sobre baño de vapor de agua, sobre la parte menos caliente de una placa calefactora, o con ayuda de rayos infrarrojos.

6. En las incineraciones de los filtros debe evitarse al máximo la producción de llamas.

7. Las calcinaciones deben hacerse en crisoles tarados, Estos deben ser, en general, de platino, excepto para las determinadas convenctonales de $\mathrm{MgO}$ y $\mathrm{SO}_{3}$, en las que pueden utilizarse de porcelana. La temperatura de calcinación deberá ser la apropiada en cada caso. En general, va bien una temperatura de $1.050^{\circ} \mathrm{C}$. El tiempo de calcinación de los crisoles vacíos deberá ser de media hora, salvo que los de platino hayan sido lavados con ácido clorhídrico, en cuyo caso deben calcinarse durante varias horas. Los enfriamientos en el desecador deben durar 5 minutos, ó 10 si se trata de la determinación de la pérdida al fuego. Las pesadas deben ser rápidas. Las recalcinaciones deben durar de 5 a 15 minutos. Deberá considerarse bien calcinado un precipitado cuando la diferencia de peso entre las calcinaciones sucesivas sea menor de 0,2 miligramos.

\section{e) Relativas a las determinaciones.}

1. En casos de duda o de exigencia de gran precisión, deberán efectuarse ensayos en blanco en condiciones idénticas a las de las determinaciones, corrigiendo, en consecuencia, los resultados de éstas. No requieren, en general, ensayos en blanco, las determinaciones de $\mathrm{Fe}_{2} \mathrm{O}_{3}$, pérdida al fuego, y álcalis por fotometría.

\section{f) Relativas a los resultados.}

1. Podrá exigirse a éstos el mismo grado de precisión que a los obtenidos por los métodos clásicos, tal como se establece, por ejemplo, en las Normas A. S. T. M. (1).

2. Se expresará con aproximación de 0,1 por 100 , o de 0,01 por 100 cuando se trate de $\mathrm{Al}_{2} \mathrm{O}_{3}$ y $\mathrm{Fe}_{2} \mathrm{O}_{3}\left(\mathrm{R}_{2} \mathrm{O}_{3}\right)$ que hayan de intervenir en el cálculo de la composición potencial del cemento, o cuando se trate de $\mathrm{Na}_{2} \mathrm{O}, \mathrm{K}_{2} \mathrm{O}, \mathrm{TiO}_{2}, \mathrm{P}_{2} \mathrm{O}_{5}, \mathrm{Mn}_{2} \mathrm{O}_{3}$ o residuo insoluble.

\subsubsection{Determinación de $\mathrm{SiO}_{2}$.}

\section{a) Fundamento.}

El método es gravimétrico y se basa en la insolubilización rápida y completa de la sílice en medio clorhídrico, por coprecipitación con gelatina y calcinación del precipitado. 


\section{b) Reactivos.}

Disolución de gelatina.-Se utilizará gelatina que no deje residuo por calcinación. Se disuelven $2,5 \mathrm{~g}$ de esta gelatina en $100 \mathrm{ml}$ de agua, calentando sobre baño de agua. La disolución es estable durante una semana.

\section{c) Procedimiento.}

Se parte de una muestra de $1 \mathrm{~g}$. Se pasa la muestra a un vaso de precipitados de $100 \mathrm{ml}$ de capacidad. Se añaden lentamente $35 \mathrm{ml}$ de ácido clorhídrico concentrado y se deshacen los grumos y pequeños terrones con una varilla de vidrio para asegurar un ataque completo.

Se tapa el vaso con un vidrio de reloj y se hace hervir su contenido durante 6 minutos, calentándolo sobre una placa calefactora. Se aparta el vaso de ésta y se añaden $15 \mathrm{ml}$ de agua fría. Se vuelve a calentar hasta principio de ebullición, se retira el vaso de la placa y se añaden, gota a gota y agitando, $7 \mathrm{ml}$ de disolución de gelatina, previamente calentada sobre baño de agua. Se agita durante 1 minuto y se deja reposar el precipitado durante otros 5 minutos.

Se filtra el líquido a través de un filtro de papel Schleicher y Schiill 238 (banda negra) o equivalente, y se recoge en un matraz aforado de $250 \mathrm{ml}$ de capacidad. El precipitado se lava con agua caliente unas 20 veces, hasta eliminar la reacción positiva de cloruros en el líquido de lavado. El filtrado y los líquidos de lavado se reservan para otras determinaciones (2.3.3 y 2.3 .4 ).

El filtro con el precipitado se deseca, incinera y calcina a $1.000^{\circ} \mathrm{C}$ durante 45 minutos, en un crisol de platino previamente pesado. Se deja enfriar en un desecador y se pesa. Se repite la calcinación hasta peso constante. Eventualmente se corrige el resultado de acuerdo con el correspondiente ensayo en blanco.

\section{d) Cálculo del resultado.}

Se calcula y expresa el resultado como $\mathrm{SiO}_{2}$ por 100 , con aproximación de 0,1 , mediante la expresión:

$$
\mathrm{SiO}_{2} \%=100 \frac{P_{2}}{P}-P_{1}
$$

en la que:

$$
\begin{aligned}
& P_{2}=\text { peso en } \mathrm{g} \text { del crisol con el residuo después de calcinación; } \\
& P_{1}=\text { peso en } \mathrm{g} \text { del crisol vacío; } \\
& P=\text { peso en } \mathrm{g} \text { de la muestra. } \\
& \text { Si } P=1 \mathrm{~g} \pm 0,0001, \quad \mathrm{SiO}_{2} \%=100\left(P_{2}-P_{1}\right)
\end{aligned}
$$

\subsubsection{Separación previa para las demás determinaciones.}

\section{a) Fundamento.}

En una parte alícuota del filtrado procedente de la determinación de la sílice se separan, por precipitación en medio amoniacal y filtración, los hidróxidos de hierro y aluminio (y eventualmente el títanio, el fósforo y el manganeso). En el líquido se determinan el óxido cálcico y la suma de óxido cálcico y óxido magnésico, de la que se halla por diferencia este último. 
El precipitado de hidróxidos se redisuelve en ácido clorhídrico y en la disolución resultante se determina la suma de óxido alumínico y óxido férrico, pero no el titanio, que no se redisuelve al tratar el precipitado con ácido clorhídrico (45).

\section{b) Disolución de lavado.}

Nitrato amónico al 2 por 100 .-Se disuelven $2 \mathrm{~g}$ de nitrato amónico en $100 \mathrm{ml}$ de agua y se añade a la disolución una gota de hidróxido amónico concentrado.

\section{c) Procedimiento.}

Del matraz de $250 \mathrm{ml}$ que contiene el filtrado procedente de la determinación de la sílice (2.3.2) se toman $100 \mathrm{ml}$ de disolución. Se pasan a un vaso de $250 \mathrm{ml}$ de capacidad y se precipitan los hidróxidos del modo siguiente: se añade a la disolución 3 ó 4 gotas de ácido nítrico concentrado y se calienta a ebullición sobre una placa calefactora. Se añade amoníaco concentrado, gota a gota y agitando, hasta precipitación completa de los hidróxidos (un pequefio exceso de hidróxido amónico se detecta por el olor a amoníaco). No debe añadirse índicador «Rojo de metilo» para apreciar el final de la precipitación de los hidróxidos-pH 7-porque podría interferir después en el viraje del indicador Calceína, en la determinación del óxido cálcico (2.3.6). Se hierve durante 2 minutos, agitando para expulsar el exceso de amoníaco. Se deja sedimentar el precipitado.

Se filtra la disolución a través de un filtro Schleicher y Schüll 240 (banda blanca) o similar y se lava el precipitado unas ocho veces con la disolución caliente de nitrato amónico hasta eliminar la reacción positiva de cloruros en el líquido de lavado. Se recoge el filtrado y los líquidos de lavado en un matraz aforado de $250 \mathrm{ml}$, y se diluye la disolución hasta enrase. En esta disolución se determina el óxido cálcico (2.3.6) y la suma de óxidos cálcico y magnésico (2.3.7).

Los hidróxidos precipitados y lavados con el filtro, se pasan al vaso en que se efectuó la precipitación, donde se tratan con $5 \mathrm{ml}$ de ácido clorhídrico concentrado y $50 \mathrm{ml}$ de agua. Se agita. Se tapa el vaso con un vidrio de reloj y se hierve durante 5 minutos para disolver el precipitado. La disolución con el filtro se mantiene sobre el baño de agua el tiempo que dura la determinación del óxido férrico (2.3.4). Después se filtra a través de un filtro Schleicher y Schüll 238 (banda negra) o similar. Se lava el filtro unas seis veces con agua caliente. El filtrado y los líquidos de lavado se recogen en un matraz aforado de $250 \mathrm{ml}$ de capacidad y se diluye hasta enrasar. En esta disolución se determina la suma de óxido alumínico y oxido férrico (2.3.5) exclusivamente, puesto que en el tratamiento con ácido clorhídrico concentrado no se disuelve el titanio que hubiera precipitado con los hidróxidos (45).

\subsubsection{Determinación de $\mathrm{Fe}_{2} \mathrm{O}_{3}$.}

\section{a) Fundamento.}

En una parte alícuota del filtrado procedente de la determinación de la sílice se reduce al estado ferroso el hierro disuelto, mediante cloruro estannoso. Se elimina con cloruro mercúrico el exceso de sal estannosa empleado. Se valora el hierro ferroso de la disolución con disolución de dicromato potásico patrón en presencia de indicador difenilaminosulfonato bárico.

\section{b) Reactivos.}

Disolución de cloruro estannoso.- $\mathrm{Se}$ disuelven $20 \mathrm{~g}$ de $\mathrm{Cl}_{2} \mathrm{Sn} \cdot 2 \mathrm{H}_{2} \mathrm{O}$ en $200 \mathrm{ml}$ de ácido clorhídrico (1:3). Se agregan unos trozos de estaño granulado, exento de hierro, y se hierve 
la disolución hasta que quede clara. Debe guardarse en un frasco cuentagotas que contenga estaño metálico.

Mezcla fosfórico-sulfúrica.-Sobre $400 \mathrm{ml}$ de agua se vierten lentamente y agitando $280 \mathrm{ml}$ de ácido fosfórico concentrado y $150 \mathrm{ml}$ de ácido sulfúrico concentrado. Se díluye con agua hasta 1 litro.

Indicador de difenilaminosulfonato bárico-Se disuelven $0,5 \mathrm{~g}$ de difenilaminosulfonato bárico en $100 \mathrm{ml}$ de agua. Se guarda la disolución en un frasco cuentagotas.

Disolución patrón de dicromato potásico.-Se disuelven $2,4570 \mathrm{~g} \mathrm{de} \mathrm{Cr}_{2} \mathrm{O}_{7} \mathrm{~K}_{2}$ en agua y se diluye la disolución hasta 1 litro: $1 \mathrm{ml}$ de esta disolución equivale exactamente a $0,004 \mathrm{~g}$ de $\mathrm{Fe}_{2} \mathrm{O}_{3}$. (Si la disolución fuese $0,05 \mathrm{~N}$, cada $1 \mathrm{ml}$ de ella equivaldría exactamente a 3,9925 mg de $\mathrm{Fe}_{2} \mathrm{O}_{3}$, valor para el que, por aproximación, puede tomarse $4,0 \mathrm{mg}$ de $\mathrm{Fe}_{2} \mathrm{O}_{3}$. La disolución $0,05 \mathrm{~N}$ contiene $2,4518 \mathrm{~g}$ de $\mathrm{Cr}_{2} \mathrm{O}_{7} \mathrm{~K}_{2}$ por litro).

\section{c) Procedimiento.}

Del matraz aforado de $250 \mathrm{ml}$ que contiene el filtrado procedente de la determinación de la sílice (2.3.2) se toman $100 \mathrm{ml}$ de disolución. Se pasan a un vaso de $250 \mathrm{ml}$ de capacidad. Se calienta a ebullición y se añade disolución de cloruro estannoso, para reducir el hierro al estado ferroso, agitando hasta decoloración completa del líquido. Se añade una gota en exceso. Se enfría la disolución lo más rápidamente posible y se añaden de una sola vez $10 \mathrm{ml}$ de disolución saturada, fría, de cloruro mercúrico. Se agita enérgicamente durante 1 minuto y se añaden $15 \mathrm{ml}$ de la mezcla fosfórico-sulfúrica. Se agregan cinco gotas de indicador.

Se valora el líquido con disolución patrón de dicromato potásico hasta viraje del indicador al color azul-violeta persistente durante 15 segundos. El indicador viene a consumir, en las condiciones de trabajo expuestas, $0,05 \mathrm{ml}$ de disolución patrón de dicromato potásico.

\section{d) Cálculo del resultado.}

Al volumen en $\mathrm{ml}$ de dicromato patrón gastado en la valoración debe restársele $0,05 \mathrm{ml}$.

Se calcula el resultado como $\mathrm{Fe}_{2} \mathrm{O}_{3}$ por 100, con aproximación de 0,01 , mediante la expresión:

$$
\mathrm{Fe}_{2} \mathrm{O}_{3} \%=100 \frac{0,004\left(V_{1}-0,05\right)}{2 / 5 P}=-\frac{V_{1}-0,05}{P}
$$

en la que:

$V_{1}=$ volumen en $\mathrm{ml}$ de disolución patrón de dicromato potásico gastado;

$P \quad=$ peso en $g$ de la muestra;

$2 / 5$ = parte alícuota de la muestra inicial;

$0,004=$ equivalente en $\mathrm{g}$ de $\mathrm{Fe}_{2} \mathrm{O}_{3}$ de $1 \mathrm{ml}$ de disolución patrón de $\mathrm{Cr}_{2} \mathrm{O}_{7} \mathrm{~K}_{2}$.

Si $P=1 \mathrm{~g} \pm 0,0001, \mathrm{Fe}_{2} \mathrm{O}_{3} \%=V_{1}-0,05$.

\subsubsection{Determinación de $\mathrm{Al}_{2} \mathrm{O}_{3}$.}

\section{a) Fundamento.}

En una parte alícuota de la disolución que contiene los hidróxidos redisueltos, se añade un exceso conocido de una disolución patrón de Complexona III, con la que forman com- 
plejos el aluminio y el hierro a $\mathrm{pH} 4,5$. El titanio queda sin redisolverse al tratar el precipitado de hidróxidos con ácido clorhídrico (45) y por lo tanto no puede formar complejo con la Complexona III en las condiciones de trabajo.

El exceso de Complexona III se valora con una disolución patrón de $\mathrm{Zn}^{2 *}$, empleando Ditizona como indicador (viraje de verde a rojo). Se determina así el consumo de disolución patrón de Complexona III correspondiente a la suma de óxido alumínico y óxido férrico. Por diferencia entre este consumo y el correspondiente al óxido férrico según 2.3 .4 , se calcula el producido por la alúmina y con él se determina el tanto por ciento de ésta. El indicador viene a consumir, en las condiciones de trabajo expuestas, $0,1 \mathrm{ml}$ de disolución patrón de $\mathrm{Zn}^{2}$.

\section{b) Reactivos.}

Disolución amortiguadora de $p H 4,5$ - - Se disuelven $126 \mathrm{~g}$ de acetato amónico en $240 \mathrm{ml}$ de ácido acético glacial y $400 \mathrm{ml}$ de agua y se diluye con agua hasta 1 litro.

Etanol de $96^{\circ}$. Disolución patrón de Complexona III $(0,01 \mathrm{M})$.-Se disuelven $3,7225 \mathrm{~g}$ de la sal disódica dihidratada del ácido etilenodiaminotetraacético (Complexona III), previamente desecada en estufa a $80^{\circ} \mathrm{C}$ durante 12 horas, hasta peso constante, en $600 \mathrm{ml}$ de agua. Se diluye la disolución con agua hasta 1 litro.

Disolución patrón de $Z \mathrm{Zn}^{2+}(0,01 \mathrm{M})$.-Se disuelven $0,8138 \mathrm{~g}$ de óxido de zinc, previamente calcinado a $1.000^{\circ} \mathrm{C}$ durante 1 hora, en $500 \mathrm{ml}$ de agua y la cantidad de ácido clorhídrico necesaria para lograr la disolución completa. El ácido se añade gota a gota y agitando. La disolución se diluye con agua hasta 1 litro.

Indicador Ditizona.-Se pulverizan en un mortero de ágata y se mezclan intimamente 0,025 gramos de Ditizona y $1 \mathrm{~g}$ de cloruro sódico.

\section{c) Procedimiento.}

Del matraz de $250 \mathrm{ml}$ que contiene los hidróxidos redisueltos (2.3.3) se tomán con una pipeta $50 \mathrm{ml}$ de disolución y se pasan a un vaso de $250 \mathrm{ml}$ de capacidad.

Se añade un volumen de disolución patrón $0,01 \mathrm{M}$ de Complexona III, perfectamente conocido y medido con bureta. Este volumen puede ser de $20 \mathrm{ml}$. A continuación se añaden 25 mililitros de la disolución amortiguadora de $\mathrm{pH} \mathrm{4,5}$. Se bierve el líquido durante 5 minutos y se enfría con agua lo más rápidamente posible. Una vez fría la disolución, se añaden $80 \mathrm{ml}$ de etanol de $96^{\circ}$, se vuelve a enfriar por completo y se añade una pequeña porción de indicador.

Se valora el líquido con disolución patrón de $\mathrm{Zn}^{2+} 0,01 \mathrm{M}$ hasta viraje del indicador verde al rojo. El indicador viene a consumir, en las condiciones de trabajo expuestas, $0,1 \mathrm{ml}$ de disolución patrón de $\mathrm{Zn}^{2+} 0,01 \mathrm{M}$.

\section{d) Cálculo del resultado.}

Al volumen en $\mathrm{ml}$ de disolución patrón de $\mathrm{Zn}^{2+} 0,01 \mathrm{M}$ gastados en la valoración se debe restar 0,1 mililitro.

Se calcula el contenido de alúmina como $\mathrm{Al}_{2} \mathrm{O}_{3}$ por 100 , con aproximación de 0,01 , y se expresa con aproximación de 0,1, restando del volumen de Complexona III empleado en la valoración conjunta de $\mathrm{Al}_{2} \mathrm{O}_{3}$ y $\mathrm{Fe}_{2} \mathrm{O}_{3}$, según 2.3.5, el volumen de Complexona III que corresponde al $\mathrm{Fe}_{2} \mathrm{O}_{3}$ contenido en una parte alícuota igual de muestra. Este volumen de Complexona III se puede calcular a partir de la expresión del tanto por ciento de $\mathrm{Fe}_{2} \mathrm{O}_{3}$ según 2.3.4, 
si se tiene en cuenta que $1 \mathrm{ml}$ de la disolución patrón de $\mathrm{Cr}_{2} \mathrm{O}_{7} \mathrm{~K}_{2}$ (equivalente a $0,004 \mathrm{~g}$ de $\left.\mathrm{Fe}_{2} \mathrm{O}_{3}\right)$ equivale a su vez a $5 \mathrm{ml}$ de disolución $0,01 \mathrm{M}$ de Complexona III. A $\left(V_{1}-0,05\right) \mathrm{ml}$ de dicromato potásico gastados en el $\mathrm{Fe}_{2} \mathrm{O}_{3}$ de una parte alícuota de $2 / 5$ de la muestra inicial corresponde $5\left(V_{1}-0,05\right) \mathrm{ml}$ de Complexona III $0,01 \mathrm{M}$. A una parte alícuota de $2 / 25$ de la muestra inicial (igual a la empleada en la determinación conjunta de $\mathrm{Al}_{2} \mathrm{O}_{3}$ y $\mathrm{Fe}_{2} \mathrm{O}_{3}$ ) corresponderá un volumen de $V-0,05 \mathrm{ml}$ de Complexona III 0,01 $\mathrm{M}$.

El tanto por ciento de alúmina viene dado, por lo tanto, por la siguiente expresión:

$$
\begin{gathered}
\mathrm{Al}_{2} \mathrm{O}_{3} \%=100\left[\frac{V_{2}-V_{3} \cdot E}{2 / 25 P}-\frac{V_{1}-0,05}{2 / 25 P}\right] \cdot 5,098 \cdot 10^{-4}=0,05098 \frac{12,5\left(V_{2}-V_{3} \cdot E-V_{1}+0,05\right)}{P}= \\
=0,63 \% 22=\frac{V_{2}-V_{3} \cdot E-V_{1}+0,05}{P}
\end{gathered}
$$

en la que:

$V_{2}=$ volumen en $\mathrm{ml}$ de disolución patrón de Complexona III añadido;

$V_{3}=$ volumen en $\mathrm{ml}$ de disolución patrón de $\mathrm{Zn}^{2+}$ gastado en la valoración del exceso de Complexona III;

$E=$ equivalente en $\mathrm{ml}$ de disolución patrón de Complexona III de $1 \mathrm{ml}$ de disolución patrón de $\mathrm{Zn}^{2+}$;

$V_{1}=$ volumen en $\mathrm{ml}$ de disolución patrón de dicromato potásico gastado en la valoración del $\mathrm{Fe}_{2} \mathrm{O}_{3}$ según 2.3.4.

$P=$ peso en $\mathrm{g}$ de la muestra;

$2 / 25=$ parte alícuota de la muestra inicial, utilizada en la valoración;

$5,098 \cdot 10^{-4}=$ equivalente en $\mathrm{g}$ de $\mathrm{Al}_{2} \mathrm{O}_{3}$ de $1 \mathrm{ml}$ de disolución patrón de Complexona III.

Si $p=1 \mathrm{~g} \pm 0,0001, \mathrm{Al}_{2} \mathrm{O}_{3} \%=0,637225\left(V_{2}-V_{3} \cdot E-V_{1}+0,05\right)$.

Este resultado no incluye $\mathrm{TiO}_{2}(45)$.

\subsubsection{Determinación de $\mathrm{CaO}$.}

\section{a) Fundamento.}

En una parte alícuota del filtrado resultante de separar los hidróxidos, la cual contiene el calcio y el magnesio en disolución, se forma el complejo del primero valorando con disolución patrón de Complexona III a pH alcalino elevado. Se emplea Calceína como indicador. En tales condiciones no se forma el complejo magnésico.

\section{b) Reactivos.}

Disolución de hidroxido sodico $4 \mathrm{~N}$.-Se disuelven $16 \mathrm{~g}$ de $\mathrm{NaOH}$ en $100 \mathrm{ml}$ de agua.

Disolución patrón de Complexona $I I I(0,01 M)$.-Véase 2.3.5.

Indicador de Calceina.-Se pulverizan en un mortero de ágata y se mezclan íntimamente $0,004 \mathrm{~g}$ de Calceína y $1 \mathrm{~g}$ de cloruro sódico. $\mathrm{El}$ indicador así preparado tiene una duración de 10 días. 


\section{c) Procedimiento.}

Del matraz de $250 \mathrm{mI}$ que contiene el filtrado procedente de la separación de los hidróxidos (2.3.3) se toman con una pipeta $20 \mathrm{ml}$ de disolución. Se pasan a un vaso de forma baja, de $250 \mathrm{ml}$ de capacidad. Se añaden $5 \mathrm{ml}$ de disolución de hidróxido sódico $4 \mathrm{~N}$ y $80 \mathrm{ml}$ de agua. Se agita enérgicamente. Se añade $0,10 \mathrm{~g}$ de indicador.

Se valora el líquido con disolución patrón de Complexona III 0,01 $\mathrm{M}$ hasta viraje del indicador del verde amarillento al rosa persistente.

d) Cálculo del resultado.

Se calcula y expresa el resultado como CaO por 100 , con aproximación de 0,1 , mediante la expresión:

$$
\mathrm{CaO} \%=100 \frac{5,608 \cdot 10^{-4} \cdot V_{4}}{1 / 31,25 P}=1,7525 \frac{V_{4}}{P}
$$

en la que:

$V_{4}=$ volumen en $\mathrm{ml}$ de disolución patrón de Complexona III gastados en la valoración;

$P=$ peso en g de la muestra;

$1 / 31,25=2 / 5 \cdot 1 / 12,5$, parte alícuota de la muestra inicial, utilizada en la valoración;

$5,608 \cdot 10^{-4}=$ equivalente en $\mathrm{g}$ de $\mathrm{CaO}$ de $1 \mathrm{ml}$ de disolución patrón de Complexona IIJ.

Si $P=1 \mathrm{~g} \pm 0,0001, \mathrm{CaO} \%=1,7525 V_{4}$.

\subsubsection{Determinación de Mgo.}

a) Fundamento.

En una parte alícuota del filtrado resultante de separar los hidróxidos, la cual contiene el calcio y el magnesio, se forman complejos de ambos valorando con disolución patrón de Complexona III a pH 10. Se emplea Negro de eriocromo $\mathrm{T}$ como indicador. Se determina así el consumo de disolución patrón de Complexona III correspondiente a la suma de óxido cálcico y óxido magnésico. Por diferencia entre este consumo y el correspondiente al óxido cálcico según 2.3.6, se calcula el producido por el óxido magnésico y con él se determina el tanto por ciento de éste.

\section{b) Reactivos.}

Disolución amortiguadora de $p H$ 10.-Se disuelven $24 \mathrm{~g}$ de cloruro amónico en $80 \mathrm{ml}$ de amoníaco concentrado y la cantidad de agua necesaria hasta 1 litro.

Disolución patrón de Complexona III $(0,01 M)$.-Véase 2.3.5.

Indicador Negro de eriocromo $T$.-Se añade directamente una pequeña porción del mismo a la disolución que se valora.

Indicador Rojo de metilo $(0,1$ por 100$)$. - Se disuelve $0,1 \mathrm{~g}$ de indicador en $100 \mathrm{ml}$ de agua o de etanol. 


\section{c) Procedimiento.}

Del matraz de $250 \mathrm{ml}$ que contiene el filtrado procedente de la separación de los hidróxidos (2.3.3) se toman con una pipeta $10 \mathrm{ml}$ de disolución. Se pasan a un vaso de forma baja, de $250 \mathrm{ml}$ de capacidad. Se añaden $25 \mathrm{ml}$ de disolución amortiguadora de $\mathrm{pH} 10$, y $80 \mathrm{ml}$ de agua. A continuación se añaden no más de dos gotas de indicador Rojo de metilo y una pe queña porción de indicador Negro de eriocrcmo $\mathrm{T}$ hasta que la disolución tome un color rojo-vino.

Se valora el líquido con disolución patrón de Complexona III $0,01 \mathrm{M}$, para lo cual se aña den primeramente unos $13 \mathrm{ml}$ de la misma. Se añade acto seguido una nueva porción de indicador, si fuera necesario, hasta que la disolución vuelva a tomar el color rojo vino anterior. Se continúa valorando hasta viraje del indicador del rojo al verde. (El viraje del Negro de eriocromo $\mathrm{T}$ es del rojo al azul celeste claro, pero en presencia de Rojo de metilo, que a pH 10 es amarillo, la tonalidad final es verde.)

\section{d) Cálculo del resultado.}

Se calcula y expresa el resultado como MgO por 100 , con aproximación de 0,1 , mediante la expresión:

$$
\mathrm{MgO} \%=100 \frac{V_{5}-V_{4} / 2}{1 / 62,5 P} \cdot 4,032 \cdot 10^{-4}=2,52 \frac{V_{5}-V_{4} / 2}{P}
$$

en la que:

$V_{5}=$ volumen en ml de la disolución patrón de Complexona III gastado en la valoración;

$V_{4}=$ volumen en $\mathrm{ml}$ de la disolución patrón de Complexona III gastado en la valoración de CaO según 2.3.6;

$p=$ peso en $g$ de la muestra;

$1 / 62,5=2 / 5 \cdot 1 / 25$, parte alícuota de la muestra inicial, utilizada en la valoración; $4,032 \cdot 10^{-4}=$ equivalente en $\mathrm{g}$ de $\mathrm{MgO}$ de $1 \mathrm{ml}$ de disolución patrón de Complexona III.

Si $P=1 \mathrm{~g} \pm 0,0001 \%, \mathrm{MgO} \%=2,52\left(V_{5}-\mathrm{V}_{4} / 2\right)$.

\subsubsection{Determinación de $\mathrm{TiO}_{2}$.}

\section{a) Fundamento.}

En una parte alícuota del filtrado procedente de la determinación de la sílice (los $50 \mathrm{ml}$ restantes de los $250 \mathrm{ml}$ ) se separan por precipitación en medio amoniacal los hidróxidos de hierro y aluminio y con ellos el titanio. El precipitado se redisuelve con ácido sulfúrico concentrado, en cuyas condiciones se redisuelve también el titanio que haya precipitado con los hidróxidos de aluminio y hierro (45). Se oxida la disolución con peróxido de hidrógeno para formar el complejo pertitánico amarillo, y se oxidan simultáneamente, y en las mismas condiciones, cantidades crecientes y conocidas de una disolución patrón de titanio, de concentración también conocida, hasta que la intensidad del color amarillo iguale a la del problema, comparando ambas. De la cantidad de disolución patrón empleada y de su equivalente en $\mathrm{TiO}_{2}(\mathrm{~g} / \mathrm{ml})$ se deduce el contenido de $\mathrm{TiO}_{2}$ del problema. Para la comparación se utilizan dos tubos Nessler iguales. 


\section{b) Reactivos.}

Disolución de lavado: Nitrato amónico al 2 por 100.-Véase 2.3.3.

Disolución patrón de sulfato titánico.-Se obtiene a partir de una muestra patrón primario de $\mathrm{TiO}_{2}$ (del National Bureau of Standars, por ejemplo), de la que se toma una cantidad perfectamente pesada, y comprendida entre 0,20 y $0,21 \mathrm{~g}$. El peso se corrige de acuerdo con la pérdida al fuego de la muestra, determinada por desecación de $1 \mathrm{~g}$ de la misma en estufa a $105-110^{\circ} \mathrm{C}$ durante 2 horas.

Se pasa la muestra a un matraz Erlenmeyer de $125 \mathrm{ml}$ de capacidad, se añaden $5 \mathrm{~g}$ de sulfato amónico y $10 \mathrm{ml}$ de ácido sulfúrico y se coloca un embudo vástago corto en el cuello del matraz. Se calienta hasta principio de ebullición, moviendo el matraz sobre la llama libre de un quemador. Se continúa calentando hasta disolución completa de la muestra.

Se enfría la disolución y se vierte en $200 \mathrm{ml}$ de agua fría, agitando enérgicamente. Se enjuaga el matraz y el embudo con ácido sulfúrico (1:19), se agita y se deja el líquido en reposo durante 24 horas. Se filtra y se recoge el filtrado y los líquidos de los lavados hechos con ácido sulfúrico (1:19) en un matraz aforado de 1 litro, diluyendo hasta la marca con ácido sulfurico (1:19).

El equivalente en $\mathrm{TiO}_{2}$ de la disolución $(\mathrm{g} / \mathrm{ml})$ será igual al peso de la muestra utilizada, por su riqueza en $\mathrm{TiO}_{2}$ (tanto por ciento), dividido por 1.000 .

\section{c) Procedimiento.}

Del matraz de $250 \mathrm{ml}$ que contiene el filtrado procedente de la determinación de la sílice (2.3.2) se toman los restantes $50 \mathrm{ml}$. Se pasan a un vaso de $250 \mathrm{ml}$ de capacidad y se precipitan, filtran y lavan los hidróxidos como en 2.3.3.

Los hidróxidos precipitados y lavados se disuelven en $30 \mathrm{ml}$ de agua y $2 \mathrm{ml}$ de ácido sulfúrico concentrado, en el mismo vaso en que se efectuó la precipitación. Se tapa con un vidrio de reloj y se hierve durante 5 minutos para disolver totalmente el precipitado. En estas condiciones se disuelve también el titanio precipitado. Se filtra la disolución a través de un filtro Schleicher y Schüll 238 (banda negra) o similar y se recoge en un matraz aforado de $50 \mathrm{ml}$. Se lava con agua caliente hasta enrasar.

En cada uno de dos tubos Nessler iguales, A y B, se ponen, respectivamente, los $50 \mathrm{ml}$ de la disolución problema y $50 \mathrm{ml}$ de agua. Se añaden a cada uno $10 \mathrm{ml}$ de peróxido de hidrógeno de 30 volúmenes y se homogeneiza por agitación el contenido de ambos. El tubo A se pondrá amarillo por la formación del complejo pertitánico, mientras que el $\mathrm{B}$ queda incoloro. Mediante una bureta se van añadiendo a éste, gota a gota, cantidades sucesivas de la disolución patrón de titanio hasta que los dos tubos, observados verticalmente sobre un fondo adecuado, presenten la misma intensidad de coloración amarilla. Se anota el consumo de disolución patrón.

\section{d) Cálculo del resultado.}

Se calcula y expresa el resultado como $\mathrm{TiO}_{2}$ por 100 , con aproximación de 0,01 , mediante la expresión:

$$
\mathrm{TiO}_{2} \%=100 \frac{V_{6}}{1 / 5 P} E=500 E \frac{V_{6}}{P}
$$

en la que:

$V_{6}=$ volumen en ml de disolución patrón de $\mathrm{TiO}_{\overline{2}}$ gastado en la igualación de color; 
$P=$ peso en $g$ de la muestra;

$1 / 5=$ parte alícuota de la muestra inicial, utilizada en la valoración;

$E=$ equivalente en $\mathrm{TiO}_{2}$ de $1 \mathrm{ml}$ de disolución patrón.

Si $P=1 \mathrm{~g} \pm 0,0001, \mathrm{TiO}_{2} \%=500 E V_{6}$.

\subsubsection{Determinación de $\mathrm{SO}_{3}$.}

\section{a) Fundamento.}

Se ataca y disuelve una muestra de cemento. En la disolución se precipitan los sulfatos con una sal soluble de plomo. Se filtra y se lava el precipitado de sulfato de plomo formado. Se redisuelve en una cantidad perfectamente medida de disolución patrón de Complexona III en exceso, a pH 4,5. Se valora el exceso de disolución patrón de Complexona III con otra disolución patrón de $\mathrm{Zn}^{2+}$ empleando Ditizona como indicador.

\section{b) Reactivos.}

Disolución de nitrato de plomo (10 por 100). - Se disuelven $50 \mathrm{~g}$ de $\left(\mathrm{NO}_{3}\right)_{2} \mathrm{~Pb}$ en agua y se diluye hasta $500 \mathrm{ml}$.

Disolución amortiguadora de pH 4,5.-Véase 2.3.5.

Disolución de Complexona III $(0,01 M)$.-Véase 2.3.5.

Disolución patrón de $\mathrm{Zn}^{2+}(0,01)$.-Wéase 2.3.5.

Indicador Ditizona.-Véase 2.3.5.

\section{c) Procedimiento.}

Se parte de otra muestra distinta de cemento. Se pesa $1 \mathrm{~g}$. Se pasa a una cápsula de porcelana y se ataca con $50 \mathrm{ml}$ de agua y $3 \mathrm{ml}$ de ácido nítrico. Se calienta en baño de agua durante media hora, hasta disolución completa ( nenos la parte insoluble). Se filtra la disolución a través de un filtro Schleicher y Schüll 238 (banda negra) o similar, y se lava el residuo con agua caliente. El filtrado y las aguas de lavado se recogen en un matraz aforado de $100 \mathrm{ml}$. Se enrasa hasta la marca.

Con una pipeta se toman $50 \mathrm{ml}$ y se pasan a un vaso de $250 \mathrm{ml}$ de capacidad. Se añaden $10 \mathrm{ml}$ de disolución de nitrato de plomo (10 por 100), gota a gota, y agitando hasta que se forme un precipitado blanco de sulfato de plomo. Se sigue agitando durante 5 minutos. Se deja el precipitado en reposo durante 1 hora.

Se filtra a través de un filtro Schleicher y Schüll 240 (banda blanca) o similar y se lava 5 ó 6 veces con agua fría, procurando que el líquido de lavado no sobrepase los $50 \mathrm{ml}$. Se pasa el filtro con el precipitado al vaso en que se efectuó la precipitación, se añaden $25 \mathrm{ml}$ de disolución patrón de Complexona III $0,01 \mathrm{M}$ exactamente medidos con bureta, y a continuación $15 \mathrm{ml}$ de disolución amortiguadora de $\mathrm{pH} 4,5$. Se agita enérgicamente hasta que se disuelva el precípitado, calentando si fuera preciso y enfriando después. Se añaden $80 \mathrm{ml}$ de etanol de $96^{\circ}$ y una pequeña porción del indicador. La disolución toma un color verde-musgo.

Se valora el exceso de disolución de Complexona III $0,01 \mathrm{M}$ con disolución patrón de $\mathrm{Zn}^{2+}$ $0,01 \mathrm{M}$ hasta viraje del indicador del verde al rojo. 
d) Cálculo del resultado.

Se calcula y expresa el resultado como $\mathrm{SO}_{3}$ por 100, con aproximación de 0,1, mediante la expresión:

$$
\mathrm{SO}_{3} \%=100 \frac{V_{7}-V_{8} \cdot E+1,5}{1 / 2 P} 8 \cdot 10^{-4}=0,16 \frac{\left(V_{7}-V_{8} \cdot E+1,5\right)}{P}
$$

en la que:

$V_{7}=$ volumen en ml de disolución patrón de Complexona III añadido;

$V_{\mathrm{g}}=$ volumen en $\mathrm{ml}$ de disolución patrón de $\mathrm{Zn}^{2+}$ gastados en la valoración del exceso de Complexona III;

$E=$ equivalente en $\mathrm{ml}$ de disolución patrón de Complexona III de $1 \mathrm{ml}$ de disolución patrón de $\mathrm{Zn}^{2+}$;

$P=$ peso en $g$ de la muestra;

$8 \cdot 10^{-4}=$ equivalente en $\mathrm{g}$ de $\mathrm{SO}_{3}$ de $1 \mathrm{ml}$ de disolución patrón de Complexona III;

$1,5=\mathrm{m} 1$ de đisolución petrón de Complexona III, que equivalen al $\mathrm{SO}_{3}$ correspondiente al $\mathrm{SO}_{4} \mathrm{~Pb}$ que queda en disolución en las condiciones de trabajo, dada la solubilidad del sulfato de plomo.

\subsubsection{Determinación de la pérdida al fuego.}

Se procede según el P. C. C. H. 61 (50).

\subsubsection{Determinación del residuo insoluble.}

Se procede según el P. C. C. H. 61 (50).

\subsubsection{Resultados.}

Los expuestos en (6) se comparan con los del método gravimétrico clásico. En la comparación se utilizan resultados de un mismo operador y de operadores distintos, obtenidos con 10 y 20 muestras de diferentes cementos. También se consideran los resultados de 10 determinaciones hechas con un mismo cemento, y de otras 5 llevadas a cabo con la muestra patrón número 177 del N. B. S. (National Bureau of Standars de Washington), cuyos datos analíticos (medios de 14 laboratorios) están certificados por este organismo norteamericano y se indican en el lugar correspondiente (6).

Del análisis de estos resultados se saca la conclusión de que el método complexométrico descrito con todo detalle en 2.3 , realizado en plan de marcha analítica sistemática y rápida para el cemento portland, da resultados plenamente satisfactorios y aceptables, tanto desde el punto de vista de la precisión analítica exigida en todos los casos, como desde el de reproducibilidad.

\subsubsection{Rapidez del método. Estudio de tiempos.}

Cuando se practica el método complexométrico tal como se ha descrito en 2.3 .1 a 2.3.11, es posible efectuar el análisis cuantitativo completo de un cemento en un período aproximado 
de 3 horas, a condición de organizar el trabajo de una forma racional. Esto representa mucho, si se tiene en cuenta que por los métodos convencionales, el tiempo empleado es de dos jornadas de trabajo.

Lo anterior queda de manifiesto cuando se proyecta y ejecuta un estudio de tiempos y operaciones, y en el caso del Departamento de Química del I. E. T. c. c. fue llevado a cabo en la forma siguiente: un operador A, actuando de observador, cronometró el trabajo de otro operador B. Después se cambiaron los papeles y el operador B cronometró el trabajo del operador A. En cada caso se repitió el proceso analítico tres veces (seis en total) y en todas ellas se observó una concordancia prácticamente absoluta entre los tiempos registrados.

Los resultados se exponen en la tabla adjunta. En ella se indican: en la columna II los tiempos invertidos en cada grupo de operaciones detallado en la columna IV; en la III, los conceptos analíticos a cuya determinación corresponden los tiempos de la columna II y los grupos de operaciones de la IV; en la IV, los grupos de operaciones correspondientes a cada concepto analítico, los cuales van numerados al margen, indicándose en cada caso el número del grupo anterior o posterior, con lo que cada operación enlaza.

\section{DISTRIBUCION DE TIEMPO Y OPERACIONES EN EL ANALISIS COMPLEXOMETRICO DEL CEMENTO PORTLAND}

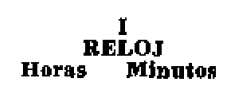

TI INVEETIDOS

0

00

15

0

$$
15
$$$$
0
$$

01

0

d

28

0

04

0

32

0

06

38
$\mathrm{SiO}_{2}$ y P. F.

SO,

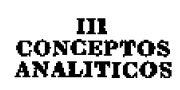

$\mathrm{SiO}_{2}$

$$
\mathrm{SiO}_{2}
$$

SiO. y P. F.
$R_{x} O_{y} y \mathrm{Fe}_{2} \mathrm{O}_{5}$

\section{OPERACIONES}

1. Se pesa $y$ ataca la muestra.

Se hierve durante seis minutos.

Se añade agua fría.

2. Se ponen dos crisoles de platino a calcinar sobre dos quemadores Mecker, hasta peso constante -5-.

3. Se ataca la muestra con agua caliente y ácido nítrico. Se deshacen los grumos.

Se cubre el vaso y se pone a calentar sobre baño de agua $-6-$

4. Se filtra el precipitado de $\mathrm{SiO}_{2}$. (Disolución $1: 250 \mathrm{ml}$ ).

Se lava 10 veces con agua muy caliente $-5-$.

Se enrasa con agua fría $y$ se pone el matraz a enfriar -7 -

5. Se retiran los crisoles de los quemadores -2-

Se dejan enfríar y se pesan.

Se pasa el precipitado de $\mathrm{SiO}_{2}-4-$ a uno de los crisoles.

Se pone a calcinar sobre un quemador Mecker - $-12-$.

Se pesa en el otro crisol una muestra de cemento y se mete en la mufla.

6. Se filtra la disolución -3-. (Disolución 2 : $100 \mathrm{ml}$ ).

Se lava con agua muy caliente casi hasta enrasar.

Se pone el matraz a enfríar $-10-$.

04

$0 \quad 42$

$\mathrm{R}_{\mathbf{r}} \mathrm{O}_{\mathbf{*}}$

7. Se enrasa el matraz con la disolución $1-4-$ -

Se homogeneiza la disolución.

Se toman con pipeta $100 \mathrm{ml}$ para $R_{x} O_{z}-8-8$.

$\mathrm{Se}$ toman otros $100 \mathrm{ml}$ para $\mathrm{Fe}_{2} \mathrm{O}_{1}$.

8. Se añaden tres gotas de $\mathrm{NO}_{3} \mathrm{H}$ concentrado a los $100 \mathrm{ml}$ para $R_{,} O_{y}-7-$

Se calienta a ebullición.

Se afiade $\mathrm{NH}_{4} \mathrm{OH}$ concentrado.

Se hierve durante dos minutos.

Se pone a calentar la disolución de $\mathrm{NO}_{3} \mathrm{NH}_{4}$ para lavados.

Se deja sedimentar durante dos minutos el precipitado de hidróxidos.

Se filtra. (Disolución $3: 250 \mathrm{ml}$ ) $-15-$.

Se lava cinco veces con $\mathrm{NO}_{1} \mathrm{NH}_{4}-9-$. 

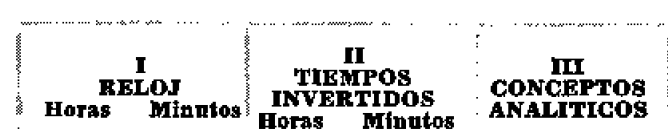

\section{IV \\ OPERA CIONES}

100

0

1

09

09

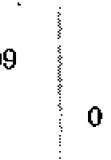

16

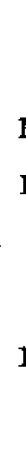

1

37

30

$2 \quad 07$

0

17

$2 \quad 24$

10

$2 \quad 34$

$\mathrm{SiO}_{2}$

0

06

240

SO,

20

3

00

3

00

Calculos

$\mathrm{Al}_{2} \mathrm{O}$
9. Se disuelven los hidróxidos con agua caliente y ClH concentrado.

Se hierve durante cinco minutos.

Se deja la disolución sobre baño de agua -11-.

10. Se enrasa el matraz con la disolución $2-6-6$

Se homogeneiza la disolución.

So toman con pipeta $50 \mathrm{ml}$.

Se añaden $10 \mathrm{ml}$ de $\left(\mathrm{NO}_{3}\right)_{2} \mathrm{~Pb}(10 \%)$.

Se agita. Se deja en reposo.

11. Se filtra la disolución de los hidróxidos $\rightarrow 9$

Se lava el filtro con agua muy caliente.

Se recoge el filtrado y las aguas de lavado en un matraz aforado de $250 \mathrm{ml}-14$ -

Se pone el matraz a enfriar.

12 Se mete en la mufla el crisol con el $\mathrm{SiO}_{2}-5$ -

13. Se calientan a ebullición los $100 \mathrm{ml}$ tomados para $\mathrm{Fe}_{2} \mathrm{O}_{3}-7-$. Se decoloran con $\mathrm{Cl}_{2} \mathrm{Sn}$ añadido gota a gota.

$\mathrm{Se}$ enfría. Se añade $\mathrm{Cl}_{2} \mathrm{Hg}$. Se agita.

Se añade la mezcla fosfórico-sulfúrica y el indicador.

Se valora con $\mathrm{Cr}_{2} \mathrm{O}_{7} \mathrm{~K}_{2} 0,05 \mathrm{~N}$ y se anota el consumo.

14. Se enrasa el matraz que contiene la disolución de los hidróxidos -11-. Se homogeneiza.

Se toman con pipeta $50 \mathrm{ml}$.

Se añaden 20 ml de EDTA $0,01 \mathrm{M}$, medidos con bureta.

Se añaden $25 \mathrm{ml}$ de disolución amortiguadora de $\mathrm{pH} 4,5$.

Se hierve durante seis minutos.

Se enfría y se añaden $80 \mathrm{ml}$ de etanol.

Se vuelve a enfriar y se afiade el indicador Ditizona. Se agita.

Se valora con $\mathrm{Zn}^{+} 0,01 \mathrm{M}$ y se anota el consumo.

15. Se enrasa el matraz con la disolución $3-8-$. Se homogeneiza. Se toman con pipeta $20 \mathrm{ml}$.

Se pesa $0,1 \mathrm{~g}$ de indicador Calceína.

Se añaden $4 \mathrm{ml}$ de $\mathrm{NaOH} 4 \mathrm{~N}, 80 \mathrm{ml}$ de agua destilada y el indicador.

Se valora con EDTA 0,01 M y se anota el consumo.

16. Se toman con pipeta $10 \mathrm{ml}$ de disolución $3-8-$.

Se añaden $25 \mathrm{ml}$ de disolución amortiguadora de $\mathrm{pH} 10 \mathrm{y}$ $80 \mathrm{ml}$ de agua destilada.

Se añaden dos gotas de Rojo de metilo y Negro de eriocromo T hasta color rojo.

Se valora con EDTA 0,01 M y se anota el consumo.

17. Se saca de la mufla el crisol con la silice $-12-$ y el de la pérdida al fuego $-5-$.

Se dejan enfriar durante dos minutos, se pesan y se anotan los pesos.

18. Se filtra el precipitado de $\mathrm{SO}_{3}-10$

Se lava seis veces con un total de $50 \mathrm{ml}$ de agua fria y tres veces más.

Se pasa el filtro al vaso de la precipitación y se afiaden $25 \mathrm{ml}$ de EDTA 0,01 M medidos con bureta.

Se añaden $15 \mathrm{ml}$ de disolución amortiguadora de $\mathrm{pH} 4,5$.

Se enfría y se afiaden $80 \mathrm{ml}$ de etanol.

Se vuelve a enfriar y se añade indicador Ditizona.

Se valora con $\mathrm{Zn}^{2+} 0,01 \mathrm{M}$ y se anota el consumo.

19. Se calculan los resultados.

Como puede apreciarse, al final del análisis el reloj señala las tres horas y la suma de los tiempos parciales invertidos en las distintas operaciones totaliza también las tres horas. 
Todo esto se refiere al análisis de una sola muestra, efectuado por un solo operador, pero nada impide que éste pueda efectuar simultáneamente el análisis de dos o varias muestras, o que estos análisis se verifiquen aen serie» por dos o más operadores, repartiéndose racionalmente el trabajo. En cualquiera de estos casos el tiempo invertido por muestra en el análisis completo se reduce mucho más aún, lo que indudablemente puede tener un gran interés en los laboratorios de control de las fábricas.

\subsubsection{4, Otras ventajas del método.}

Las desventajas de los métodos clásicos quedan prácticamente eliminadas en el método complexométrico. Por una parte, su incomparable mayor rapidez queda de manifiesto en 2.3.13. Por otra, el numero de operaciones analíticas «unitarias" que hay que efectuar es mucho menor, ya que, por de pronto, se eliminan: las dos evaporaciones en la determinación de la sílice; las calcinaciones en el caso de la determinación de los hidróxidos, en el de la magnesia, en el del trióxido de azufre y, eventualmente, en el de la cal. Se eliminan también las demoras requeridas por el reposo y la sedimentación de precipitados, que en este caso no existen, lo cual contribuye a la rapidez en el análisis. Además, las operaciones analíticas restantes son mucho menos complejas, por cuanto que quedan reducidas en su gran mayoría a simples volumetrías. El número de disoluciones patrón y de reactivos es asimismo mucho menor que en el caso de los métodos tradicionales, pues la disolución de Complexona III se emplea a una concentración única de $0,01 \mathrm{M}$ para todas las determinaciones complexométricas. El material y equipo necesarios son asimismo mucho más reducidos.

Finalmente, sobre los métodos complexométricos sistemáticos dados a conocer, el propuesto en 2.3 tiene indudables ventajas frente a los inconveniente de aquéllos. Entre las ventajas figuran las de ser más completo, más sencillo, más rápido y más perfecto, sin olvidar la gran parte de trabajo original que incluye.

En efecto, uno de los mayores perfeccionamientos que indudablemente constituye una innovación, es el de determinar la alúmina como tal, es decir, como óxido alumínico, $\mathrm{Al}_{2} \mathrm{O}_{3}$, totalmente separada e independiente del bióxido de titanio, $\mathrm{TiO}_{2}$, a diferencia de los métodos clásicos e incluso de otros métodos complexométricos originales previamente propuestos. Esto permite obtener de antemano la «alúmina corregida» sin necesidad de tener que determinar $\mathrm{TiO}_{2}$ para corregirla. Esta alúmina corregida es la que verdaderamente interviene en el cálculo de la composición potencial del cemento.

Esto se ha podido comprobar en una serie de ensayos encaminados a poner de manifiesto este hecho, de cuyos resultados se ha dado cuenta en un trabajo anterior (45).

\section{CONCLUSIONES GENERALES.}

1." Desde un punto de vista "técnico», el método complexométrico expuesto para el análisis químico cuantitativo completo de un cemento es comparable, en cuanto a exactitud, precisión y reproducibilidad, con los métodos químicos tradicionales utilizados con el mismo fin, y, por lo tanto, aceptable.

2." El método complexométrico es mucho más rápido que el clásico ( 3 horas, frente a dos jornadas de trabajo, en la ejecución de un análisis completo, según uno y otro).

3." El método complexométrico es mucho más sencillo de ejecución, pues implica bastantes menos operaciones analíticas «unitarias", y las que incluye son a su vez más sencillas que la mayoria de las del método clásico, por cuanto que se reducen casi exclusivamente a volumetrías. 
4. El método complexométrico exige muchos menos reactivos y disoluciones patrón, y éstas se obtienen con facilidad, casi todas a partir de sustancias que pueden ser consideradas como patrones primarios.

5. El equipo y material necesario para la realización del método complexométrico es mucho más sencillo y reducido que el que precisa el método clásico. No requiere aparatos ni técnicas especiales.

6. Como consecuencia de ello, el método complexométrico permite disponer un pequeño laboratorio portátil, de poco peso y volumen, que resuelva las cuestiones analíticas en cualquier lugar, a pie de obra.

7.a El método complexométrico puede ser ejecutado por operadores de preparación normal, sin que requieran una especial, ni superior a la precisa para practicar los métodos convencionales.

8. En vista de cuanto precede, el método complexométrico, a diferencia del clásico, permite resolver prácticamente el problema de control de los laboratorios de fábrica.

9. Por sus características puede también ser de aplicación en laboratorios de ensayo de materiales y en investigación, y en tal sentido podría tener entrada en las Normas nacionales para cemento, e incluso en las internacionales.

10. Por el momento se está poniendo en vigor, como método normal, en el Departamento de Química del I. E. T. c. c., y podrá ser aceptado, como método alternativo y optativo, cuando menos, en el vigente Pliego de Condiciones para la Recepción de Conglomerantes Hidráulicos en Obras de Carácter Oficial.

\section{Bibliografía}

(1) A. S. T. M.: Standards, C114, parte 4 (1961)

(2) Calleja, J.: :Métodos de análisis químico del I. E. T. c. c., aplicados al cemento portland». Materiales de Construcción (Instituto Eduardo Torroja de la Construcción y del Cemento), núm. 81, 3-7 (1957).

(3) Lochez, F. W, y Richertz, W.: *Determinación rápida de la composición química de las primeras materias del cemento por métodos físicos». Zement-Kalk-Gips, núm. 1, 10 (I962).

(4) Hedr, R.: s Colorimetric methods for rapid analysis of silicate materials». Proc. Swedish Cement and Concr. Res. Inst., núm. 8 (1947).

(5) Scrnozmer: a UTber den Einsatz der Röntgentluoreszenz-Analyse in der Zementchemie». Zement-Kalk-Gips, núm. 11, $522(1960)$.

(6) Calleja, J.; Fernández Paris, J. M., y Triviño, F.: «Método complexométrico para el análisis rápido del cemento portland». Monografía núm, 233. Instituto Eduardo Torroja de la Construcción y del Cemento. Madrid (1963):

(7) Burriel, F; Lucena, F., y Arribas, S.: «Quimica Analitica Cuantitativa: Teotia y semimicrométodos», pág. 23, Editorial Paraninfo, Madrid (1952).

(8) Schwarzendach, G.: aDie Komplexometrische Titration», 3." ed., F. Enke Verlag, Stuttgart (1957).

(9) Bermejo, F.: eAplicaciones analíticas de las complexonas (volumetrias complexométricas). Información de Química Analitica, VIII/4, 119-132 (1954).

(10) Becken, F.: eLe dosage complexométrique du fer, du calcium et du magnésium dans les ciments et les substances analogues». Revue des Matérlatux, núm. 43I-432, 248 (1951).

(11) Flasches, H.: «EDTA tritationsะ. Pergamon Press, London (1959)

(12) De Seabra, A. V., y Tavanes Cravo, M. R.: aA aplicaçao das modernas técnicas físicoquímicas a analise rapida de cimentos. Complexometrías. I Congresso Infernacional do Cimento, Lisboa (1960); Memoria núm. 168 del Laboratorio Nacional de Engenharia Civil, Lishoa (1961).

(13) Pribic, R.: «Komplexometrie. Band I: Prinzipien und Grundbestimmungen*. V. E. B. Deutscher Verlag für Grunstoffindustrie, Leipzig (1960).

(14) Mantecl, A. B., y CaLvin, M.: «Die Chemie der Metall-chelat-Verbindungen*. Verlag Chemie G. m. b. H., Weínheim-Bergst. (1958). 
(15) Fittz, I. S.; Richand, M. J., y KarRaKer, S. K. : a Potentiometric titrations with (ethylene dinitrilo)-tetraacetate. Use of masking agents to improve selectivity. Anal. Chem, 30/8, 1847-1350 (1958).

(16) Mechelnynck, P.: «Solubilidad del ácido etilenodiaminotetraacético ( $\times$ Complexona II ) en función del pH. Volumetria amperométrica de la complexonax. Analyt. Chim. Acta, 19/6, 577 (1958).

(17) Asensi Mora, G. « Quimica Analítica. Proceso redox en complexornetria. I». Química e Industria, 5/6, 225-228 (1958).

(18) SEN, B.: «Volumetrías con ácido etilenodiaminotetraacético (EDTA), sin indicadores metálicos». Aralyt. Chim. Acta, $19 / 6,551(1958)$

(19) T. R. M.: a Chelatometric Indicators». Chem. Products, 21, 371 (1958). Current Chemical Papers, 11, 750 (1958); ref. en Building Science Abstracs, 32/2, 43 (1959).

(20) Korbl, I., y Phibl, R.: a Análisís químico industrial. Nuevos indicadores complexométricoss. Indusirial Chem., 34/ 406, $677(1958)$.

(21) Suk, V., y Mrketuxova, V.: *Chemische Indikatoren. V. Chelatometrischer Indikator Ericchromcyanin R, seine Acid-Basische Eigenschaften und Bildung von Metallkomplexent. Collec. Czechoslov. Chem. Comm. (Universidad de Praga), 24/11, 3629 (1959).

(22) WEst, T.: a Nuevos reactivos para el análisis complexométricos, Chem. Age, 80/2044, 444 (1958).

(28) Bermejo, F., y ReY MendozA, R.: «Aplicaciones analíticas de los quelones. XV. El ADTC como reactivo analitico». Inf. Outm. Analit., $13-31$ (1959).

(24) Bermejo, F., y Prieto, A.: «Nuevos análogos del AEDT y nuevas aplicaciones de las volumetrias quelométricas». Inf. Outm. Analit., 15/5, 385 (1961).

(25) ANalysen-Sctinellmethoden (Sammelreferat). J. Soc. Glass. Tech., 43/210 (1959).

(26) Voinovitch, I. A.: *Contribution aux analyses des silicates». Publicactón de la Société Française de Céramique. París (1956).

(27) PentienRa, J. M. : « Métodos rápidos de análisis de silicatos». Boletín Soc. Esp. Ceram., 1/6, $351-359$ (1962).

(28) KLAsse, F, y Bosch, H.: «Schnellanalyse von Roh « und Werkstoffen im Gesamtsystem Kieselsäure-Tonerde*. Tonindustrie Zeitung, $83 / 2,30$ (1959).

(29) Buzzl, S. : Contributo alla analisi rapida in cementria. L'Indtastria Italiana del Cemento, 31/2, 66-79 (1961).

(90) Bogdanova, J. V; Malamud, M. M, y Neschadimova. N. M. Tsement (U. R. S. S.), 25/2, 12 (1959),

(81) Río, A., y Tonłво, M.: ๔Aplicazione delle analisì cómplessometriche in cementeria. Determinazione degli ioni Ca, $\mathrm{Mg}$, Fe e Sr». L'Industria Italiana del Cemento, 25/6, 145-151 (1955).

(32) Chemsche Analysen:Kalk: Bundesverband der Deutschen Kalkindustrie. Kaiser-Wilhelmring 26, Köln, Alemania.

(53) Bartosch, E.: “Die analytischen Untersuchungsmethoden des Vereins der österreichischen Zementfabricanten». Zement und Beton, núm, 19, I (1960).

(34) Ritey, I.: análisis rápido de rocas y minerales que contienen silicio*. Analyt. Chim. Acta, 19/5, 413-428 (1960).

(35) Barone, P., y Frigione, G. : *Determinazione complessometrica dell'alluminto in presenza di manganeso*. L'Industria Italiana del Cemento, 31/9, 439-446 (1961).

(36) Bock, D. y SImcren, H. S.: *Aplicación del análisis rápido del crudo al control de fabricacín de cementọ. Silikattechnik, 9/2, 79-82 (1958).

(87) BarTHolom $\ddot{A}$ HaNs-Dreter : ๔eitrag zur fäjlungsfreien komplexometrischen Titration von Zementen». Tonindustrie Zeitung, núm. 10, 234-236 (I962).

(38) Strafelda, F., y Rihova. T.: «Dosage complexométrique du calcium et du magnésium avee indication potentiométrique du point fina $]_{x}$. Collect. Czechoslov. Chem. Comm. (Universidad de Praga), 25/5, 1444 (1960).

(39) URANOVSKY, $B_{3}, y$ VAN AARDT, $M_{1}$ : aThe use of disodium ethylenediaminetetraacetate in the estimation of calcium and magnesium in building materialss. S. A. Industrial Chemist, 11-7 (1957).

(40) Afanaseva, L. I.: a Aplicación de la Complexona III a la separación del bario, estroncio y calciod, Rev. Ouím. Analitica (U. R. S. S.), 14/3, 375 (1959).

(41) I. S. O.: *Standards for chemical analysis of cementsm. Citado en ref. núm. 12.

(42) Wallhaf, M. : Aparato umiversal para el análisis rápido de cementoss. Zeits. Anal. Chem., 170/2, 420-423 (1959).

(43) Babachev, G. N. : Aplicación de la complexometría al estudio de los cementos y a la dosificación de los elementos de adición. Trement (U. R. S. S.), 25/4, 30-32 (1959).

(44) Calleja, J., y Franḱndez París, J. M. «Determinación complexométrica de la alúmina en el cementos. Revisto de Ciencia Aplicada, 13/69, 326-333 (1959).

(45) Calleja, J., y Fernández París, I. M. : «Observaciones acerca de la determinación de alúmina en cementos». Matertales de Construcción (I. E. T. e. ๔), núm. 110 (1963).

(46) Calleja, T., y Fenández Paris, J. M. : « Determinación complexométrica de trióxido de azufre en cemento portlands. Revista de Ciencia Aplicada, 15/79, (2), 120-125 (1961).

(47) Calleja, I, y Fernádez Paris, T. M.: a Nuevos métodos complexométricos para la determinación de trióxido de azufre en el cemento portland. Revista de Ciencia Aplicada, 16/87 (4), 312-317 (1962).

(48) Oвrols, T.: *Determinación cuantitativa rápida de cententos por quelatometrià. Afinidad, núm. 211, 12 (1961).

(49) Ford, C. L. : «Excerpts from a cement analyst's instruction manuals. Joum. Res. Devel. Lab. (P. C. A.), 3/2, I3-21 (1961).

(50) P. C. C. H.-61: Manuales y Nomas Instituto Eduardo Torroja de la Construcción y del Cemento. Madrid (1961). 